\title{
Multinuclear diffusion NMR Spectroscopy and DFT modeling: a powerful combination for unraveling the mechanism of phosphoester bond hydrolysis catalyzed by metal-substituted polyoxometalates
}

\author{
Thi Kim Nga Luong, ${ }^{[\mathrm{a}]}$ Pavletta Shestakova, ${ }^{[\mathrm{a},[\mathrm{b}]}$ Tzvetan T. Mihaylov, ${ }^{[\mathrm{c}]}$ Gregory Absillis, ${ }^{[\mathrm{a}]}$ \\ Kristine Pierloot, ${ }^{[c]}$ and Tatjana N. Parac-Vogt*[a]
}

\begin{abstract}
In this work we propose a detailed reaction mechanism for the hydrolysis of the phosphoester bonds in the DNA model substrate bis-4-nitrophenyl phosphate (BNPP) in the presence of the $\mathrm{Zr}^{\mathrm{IV}}$-substituted Keggin type polyoxometalate $\left(\mathrm{Et}_{2} \mathrm{NH}_{2}\right)_{8}[\{\alpha-$ $\left.\left.\mathrm{PW}_{11} \mathrm{O}_{39} \mathrm{Zr}(\mu-\mathrm{OH})\left(\mathrm{H}_{2} \mathrm{O}\right)\right\}_{2}\right] \cdot 7 \mathrm{H}_{2} \mathrm{O} \quad(\mathrm{ZrK} \quad 2: 2)$ at $\mathrm{pD}$ 6.4. Low temperature ${ }^{31} \mathrm{P}$ DOSY spectra at $\mathrm{pD} 6.4$ give the first experimental evidence for the presence of ZrK 1:1 in fast equilibrium with ZrK 2:2 in pure aqueous solution. Moreover, theoretical calculations identified the ZrK 1:1 form as potentially active species in solution. The reaction intermediates involved in the hydrolysis have been identified based on ${ }^{1} \mathrm{H} /{ }^{31} \mathrm{P}$ NMR studies, including EXSY and DOSY NMR, and are supported by DFT calculations. This combined experimental/theoretical approach enabled us to determine the structures of four intermediate species in which the starting compound BNPP, nitrophenyl phosphate (NPP) or the end product phosphate $(P)$ are coordinated to ZrK 1:1. In the proposed reaction mechanism BNPP initially coordinates to ZrK $1: 1$ in a monodentate fashion resulting in hydrolysis of the first phophoester bond in BNPP and formation of NPP. EXSY NMR shows that the bidentate complex between NPP and ZrK 1:1 is in equilibrium with monobound and free NPP. Subsequently, hydrolysis of NPP results in $P$ which is in equilibrium with its monobound form.
\end{abstract}

\section{Introduction}

At physiological conditions the half-life for phosphoester bond hydrolysis in DNA and RNA has been estimated to be in the order of several hundreds of millions and hundreds of years respectively. ${ }^{[1]}$ As a result, nature has chosen this extremely stable phosphoester bond as the link between the nucleic acid building blocks in DNA and RNA to preserve the genetic material. Nevertheless, phosphoester bond hydrolysis is of major importance in a broad variety of cellular processes including DNA repair and excision, energy metabolism, and signal transduction. ${ }^{[2]}$

\footnotetext{
[a] Laboratory of Bioinorganic Chemistry, Department of Chemistry, KU Leuven, Celestijnenlaan 200F, 3001 Leuven, Belgium

E-mail: Tatjana.Vogt@chem.kuleuven.be www.chem.kuleuven.be/lbc/

[b] NMR Laboratory, Institute of Organic Chemistry with Centre of Phytochemistry, Bulgarian Academy of Sciences, Sofia, Bulgaria.

[c] Laboratory of Computational Coordination Chemistry, Department of Chemistry, KU Leuven, Celestijnenlaan 200F, 3001 Leuven, Belgium
}

Supporting information for this article is available on the WWW under http://dx.doi.org/10.1002/ejic.2014xxxxx
For these purposes nature makes use of nuclease enzymes that catalyze phosphoester bond hydrolysis with multiple turnovers at phenomenal reaction rates. For most of these enzymes this reactivity originates from a di- or multinuclear metal ion core positioned at the active site of the enzyme. This catalytic centre typically consists of metal ions such as $\mathrm{Mg}^{\prime \prime}, \mathrm{Zn}^{\prime \prime}$, $\mathrm{Fe}^{\mathrm{II}}$ and $\mathrm{Mn}$ ", all characterized by a high charge density, rapid ligand exchange kinetics, redox inactive behavior, and the availability of appropriate hydration states. As a result, both the nucleophile water and the substrate can be coordinated and activated in a cooperative metal-mediated hydrolysis mechanism. ${ }^{[3]}$

Nuclease enzymes also play a critical role in biotechnology applications. The ability to efficiently hydrolyze DNA and RNA with high selectivity at physiological conditions offers great opportunities in both genomics and the design of novel therapeutics ${ }^{[4]}$ For these purposes artificial metallonucleases as functional biomimics for nuclease enzymes are being developed. However, given the extreme stability of DNA and RNA, the engineering of metallonucleases that are highly active at physiological conditions is not a straightforward task. In recent years a broad range of mono, di-, and multinuclear metal-based artificial nucleases were synthesized and their reactivity was evaluated on DNA, RNA, and their model compounds. ${ }^{[5]}$ These metal-based artificial enzymes typically consist of first row transition or lanthanide metal ions coordinated to organic ligands such as pyridyl- and benzimidazole derivatives. Since these systems are less sophisticated compared to their counterparts found in nature, they offer the advantage of a more easy examination of the structure-activity relationship and the role of the metal ion. However, there is still much room for improvement as the reactivity of these compounds is well below the enzymatic activity of nucleases despite the use of a high catalytic excess. Moreover, very few systems have been tested for multi-turnover behavior. One proposed approach for the further development of artificial nucleases is optimized ligand design. By carefully engineering the ligand, substrate binding and activation can be improved resulting in increased reaction rates and multiple turnovers. Most commonly existing organic ligands are being modified, however, new strategies such as the use of inorganic ligands also emerge.

Polyoxometalates (POMs) are well suited for this purpose. They are generally described as inorganic metal-oxygen clusters and are characterized by a broad variety of highly tunable chemical and physical properties. ${ }^{[6]}$ As a result, they are widely 
studied in various research domains including material science ${ }^{[7]}$ medicine ${ }^{[8]}$ and catalysis. ${ }^{[9]}$ More importantly, part of their structure can be removed leading to lacunary POMs in which the vacancy can act as a ligand for various metal ions, including those found in metallonuclease enzymes. Interestingly, these so-called metal-substituted POMs have proven to be very promising promoting agents or catalysts for a range of organic reactions ${ }^{[10]}$ including the hydrolysis of the highly inert amide bonds in proteins ${ }^{[11]}$ and the hydrolysis of stable phospho(di)ester bonds in DNA and RNA model substrates. ${ }^{[12]}$ We have previously shown that the $\mathrm{Zr}^{\mathrm{IV}}$-substituted WellsDawson POM K ${ }_{15} \mathrm{H}\left[\mathrm{Zr}\left(\alpha_{2}-\mathrm{P}_{2} \mathrm{~W}_{17} \mathrm{O}_{61}\right)_{2}\right] \cdot 25 \mathrm{H}_{2} \mathrm{O}$ acted as a catalyst for phosphoester bond hydrolysis in the commonly used DNA model substrates (Figure 1) 4-nitrophenyl phosphate (NPP) and bis-4-nitrophenyl phosphate (BNPP). ${ }^{[12 a]}$ The presence of $\mathrm{Zr}^{\mathrm{IV}}$ in the POM structure was proven to be essential for phosphoester bond hydrolysis, while properties such as high Lewis acidity, rapid ligand-exchange kinetics, redox inactivity and high coordination number make this ion an ideal candidate for the envisioned application. However, because of the presence of only one hydrolytically active $\mathrm{Zr}^{\mathrm{IV}}$ center, $\mathrm{K}_{15} \mathrm{H}\left[\mathrm{Zr}\left(\alpha_{2-}\right.\right.$ $\left.\left.\mathrm{P}_{2} \mathrm{~W}_{17} \mathrm{O}_{61}\right)_{2}\right] \cdot 25 \mathrm{H}_{2} \mathrm{O}$ it is not the best representative for natural metallonuclease enzymes which often consist of a bimetallic active center. Therefore, the reactivity of the bimetallic $\mathrm{Zr}^{\mathrm{IV}}$ Keggin POM $\left(\mathrm{Et}_{2} \mathrm{NH}_{2}\right)_{8}\left[\left\{\alpha-\mathrm{PW}_{11} \mathrm{O}_{39} \mathrm{Zr}(\mu-\mathrm{OH})\left(\mathrm{H}_{2} \mathrm{O}\right)\right\}_{2}\right] \cdot 7 \mathrm{H}_{2} \mathrm{O}(\mathrm{ZrK}$ 2:2) towards NPP and BNPP was recently examined. ${ }^{[13]}$ It was shown that in the presence of ZrK 2:2 BNPP hydrolysis was accelerated by at least two orders of magnitude when compared to spontaneous BNPP hydrolysis under the same reaction conditions.

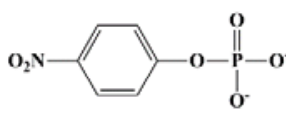

NPP

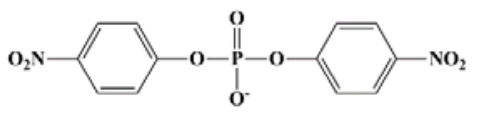

BNPP
Figure 1. Chemical structure of 4-nitrophenyl phosphate (NPP) and bis-4nitrophenyl phosphate (BNPP)

As metal-substituted POMs are often characterized by multiple equilibria in aqueous solution, the exact nature of the POM species responsible for the observed reactivity is very difficult to assess. Depending on the experimental conditions a mixture of lacunary, 1:2, 2:2, and/or 1:1 metal:POM complexes is often found. ${ }^{[14]}$ These species do not only differ in terms of the number of incorporated metal ions, but the observed metal centers also typically display different Lewis acid behavior and are characterized by a different number of coordinated water molecules. As a result some species are expected to have higher catalytic activity than others. For Zriv-substituted Keggin species the 2:2 (Figure 2a) and 1:2 species (Figure 2b) have been characterized by X-ray crystallography in the solid state and by ${ }^{31} \mathrm{P}^{183} \mathrm{~W}$ NMR in solution. ${ }^{[15]}$ Although the $2: 2$ species, having one water molecule coordinated to each $\mathrm{Zr}^{\mathrm{IV}}$ center, is supposed to display superior catalytic activity when compared to the $1: 2$ species, the $1: 1$ species with several exposed coordination sites to $\mathrm{Zr}^{\mathrm{IV}}$ would be most ideally suited for catalysis applications. Although the existence of $1: 1 \mathrm{Zr}^{\mathrm{rv}}$ substituted Keggin species has been widely anticipated, to the best of our knowledge its existence in aqueous solution as well as its isolation in the solid state has not yet been demonstrated.

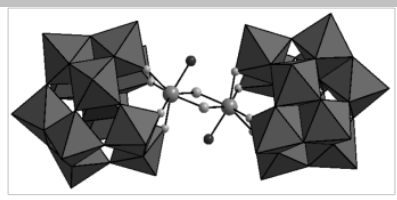

a

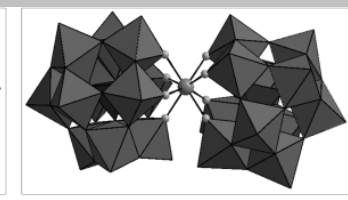

b
Figure 2. Structures of (a) $\left(\mathrm{Et}_{2} \mathrm{NH}_{2}\right)_{8}\left[\left\{\alpha-\mathrm{PW}_{11} \mathrm{O}_{39} \mathrm{Zr}(\mu-\mathrm{OH})\left(\mathrm{H}_{2} \mathrm{O}\right)\right\}_{2}\right] \cdot 7 \mathrm{H}_{2} \mathrm{O}(\mathrm{ZrK}$ 2:2) and (b) $\left(\mathrm{Et}_{2} \mathrm{NH}_{2}\right)_{10}\left[\mathrm{Zr}\left(\mathrm{PW}_{11} \mathrm{O}_{39}\right)_{2}\right] \cdot 7 \mathrm{H}_{2} \mathrm{O}$ (ZrK 1:2). The $\mathrm{WO}_{6}$ groups are represented by dark grey octahedra, while the internal $\mathrm{PO}_{4}$ groups are represented by black tetrahedra. $\mathrm{Zr}^{\mathrm{IV}}$ and oxygens of free coordinated $\mathrm{H}_{2} \mathrm{O}$ molecules are represented by big grey and black balls respectively.

In this paper we apply a unique multidisciplinary approach that includes heteronuclear $\left({ }^{1} \mathrm{H}\right.$ and $\left.{ }^{31} \mathrm{P}\right)$ 1D and 2D NMR methods such as Diffusion Ordered SpectroscopY (DOSY) and Exchange SpectroscopY (EXSY), supported by theoretical calculations in order to elucidate a detailed reaction mechanism of BNPP hydrolysis in the presence of ZrK 2:2. Both the stability and the chemical nature of the reaction intermediates as well as new aspects of the aqueous solution speciation of ZrK 2:2 are addressed, demonstrating that the combination of ${ }^{31} \mathrm{P}$ DOSY measurements and theoretical calculations is a powerful tool for unraveling the active POM species in solution. DOSY NMR has proven to be a useful tool for the investigation of interactions and aggregation phenomena, including complex colloidal systems, ${ }^{[16]}$ supramolecular ${ }^{[17]}$ and organometallic complexes. ${ }^{[18]}$ However, its usefulness for the characterization of POM based structures was only recently demonstrated by our group, opening up a wide range of possibilities for studying both POM based structures and POM catalyzed reactions. ${ }^{[19]}$

\section{Results and Discussion}

In our previous paper we have shown that ZrK 2:2 is able to efficiently hydrolyze bis-4-nitrophenyl phosphate (BNPP) at nearly neutral $\mathrm{pH}$ and $60^{\circ} \mathrm{C} .^{[13]}$ In general, in a first step BNPP is hydrolyzed to 4-nitrophenyl phosphate (NPP) and nitrophenol (NP) (Scheme 1). In a second step NPP is further hydrolyzed to a second NP molecule and phosphate $(P)$. In all stages of the reaction intermediates between the $\mathrm{POM}$ and starting or reaction products can be formed. These intermediates are abbreviated as 11,12 , and 13 and correspond to POM bound to BNPP, NPP, and $\mathrm{P}$ respectively.

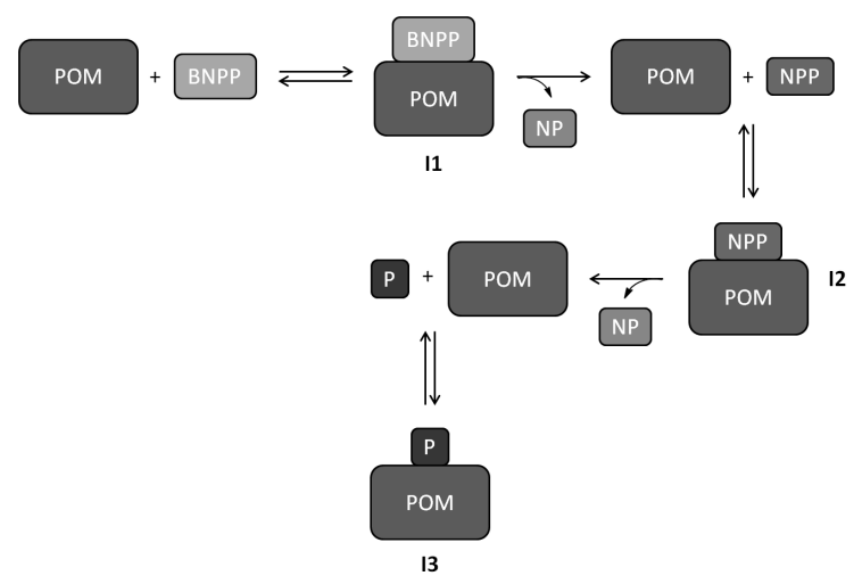

Scheme 1. Schematic representation of BNPP hydrolysis in the presence of ZrK 2:2. 
Neither NPP nor one of these intermediates was observed during the hydrolysis of $1.0 \mathrm{mM}$ of BNPP in the presence of 1.0 $\mathrm{mM} \mathrm{ZrK} \mathrm{2:2} \mathrm{at} \mathrm{pD} 6.4$ and $60^{\circ} \mathrm{C} .{ }^{[13]}$ This might be due to the fact that at these conditions the starting concentration of BNPP is rather low in terms of NMR sensitivity. Therefore, the reaction mechanism was studied at higher BNPP concentrations. Figure 3a-d shows the ${ }^{1} \mathrm{H}$ NMR spectra of a mixture of $3.0 \mathrm{mM}$ of BNPP and $3.0 \mathrm{mM}$ of $\mathrm{ZrK} 2: 2$ at $\mathrm{pD} 6.4$ and $60{ }^{\circ} \mathrm{C}$, measured after different incubation times within $26 \mathrm{~h}$. The NMR spectrum measured after $1.5 \mathrm{~h}$ at $60{ }^{\circ} \mathrm{C}$ already shows, apart from two doublets at 8.20 and $6.99 \mathrm{ppm}$ which are assigned to NP, the appearance of new signals. Two low intensity doublets were observed at 8.35 and $7.75 \mathrm{ppm}$. A careful inspection of the upfield BNPP resonance at $7.39 \mathrm{ppm}$ indicates the presence of two broad low intensity signals on both flanks of this resonance (Figure S1).

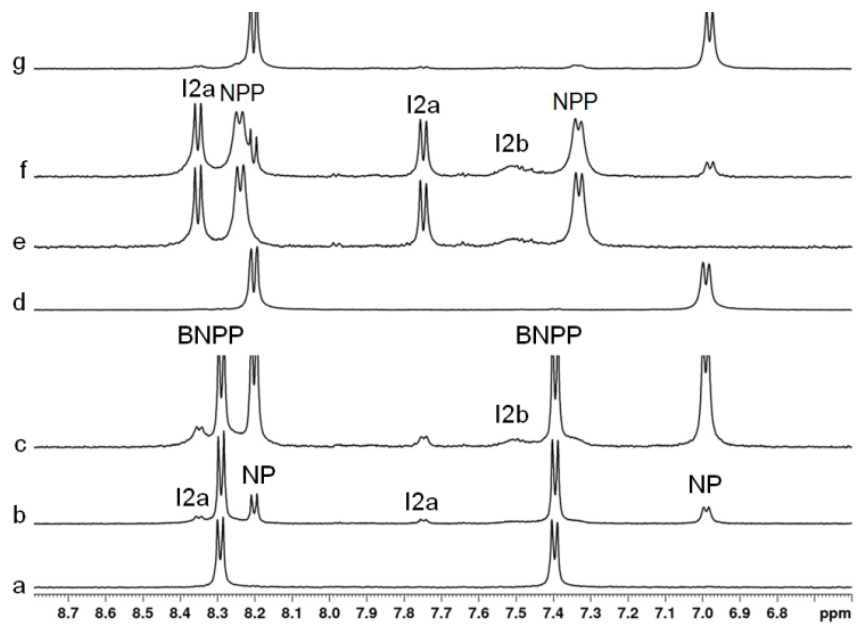

Figure 3. ${ }^{1} \mathrm{H}$ NMR of the hydrolysis reaction at $\mathrm{pD} 6.4$ and $60{ }^{\circ} \mathrm{C}$ : from (a) to (d) between $3.0 \mathrm{mM}$ of BNPP in the presence of $3.0 \mathrm{mM}$ of ZrK 2:2, measured after mixing (a), $1.5 \mathrm{~h} \mathrm{(b),} 4 \mathrm{~h}$ (c), $26 \mathrm{~h}$ (d); from (e) to (g) between $3.0 \mathrm{mM}$ of NPP in the presence of 3.0 of $\mathrm{mM}$ ZrK 2:2 measured after mixing (e), 20 min (f) and $18 \mathrm{~h} \mathrm{(g)}$.

Since the proposed reaction mechanism suggests the formation of NPP and its further hydrolysis to NP and phosphate, following an identical reaction mechanism (Scheme 1), comparative experiments of NPP hydrolysis promoted by ZrK 2:2 were also performed. Figure $3 \mathrm{e}-\mathrm{g}$ shows the ${ }^{1} \mathrm{H}$ NMR spectra of a mixture of $3.0 \mathrm{mM}$ of NPP and $3.0 \mathrm{mM}$ of ZrK 2:2 measured at certain time intervals. Comparison of the BNPP and NPP spectra clearly indicates the presence of the same species, generated during the hydrolysis of BNPP and NPP. The pair of doublets at 8.35 and 7.75 ppm, as well as the broad peak at $7.5 \mathrm{ppm}$ are also detected in the spectra of a $3.0 \mathrm{mM} \mathrm{1:1}$ NPP:ZrK 2:2 mixture, indicating that they originate from several POM bound NPP reaction intermediates. At this point the chemical nature (mono- or bidentate bound NPP) of these intermediates is not known. Therefore, the pair of doublets at 8.35 and $7.75 \mathrm{ppm}$ will be referred to as $12 \mathrm{a}$, while the broad peak at $7.5 \mathrm{ppm}$ will be assigned to $12 \mathrm{~b}$, each representing a different POM bound NPP reaction intermediate. The broad and very low intensity peak upfield from the main BNPP signal observed in the spectra of the BNPP/ZrK 2:2 mixture has an identical chemical shift as the upfield NPP resonance in the spectrum of NPP/ZrK 2:2 mixture, which proves the formation of
NPP as an intermediate during BNPP hydrolysis. The intensity of these two intermediates slightly increases with the advance of the reaction, but they disappear in the final spectrum measured after $26 \mathrm{~h}$, when the reaction is completed (Figure 4). The lack of additional signals in the spectra of BNPP:ZrK 2:2 as compared to those of NPP:ZrK 2:2 mixture indicates that most probably I1 has a very short lifetime and converts fast into 12 . We suggest that this intermediate is not very stable due to steric hindrance within the complex between the bulky BNPP molecule and the POM.

In order to answer the question whether the intermediates contribute to the rate constant of BNPP hydrolysis, the kinetics of the reaction between $6.0 \mathrm{mM}$ of BNPP and $6.0 \mathrm{mM}$ of ZrK 2:2, in which the presence of both $12 \mathrm{a}$ and $12 \mathrm{~b}$ are visible, was determined at $\mathrm{pD} 6.4$ and $60^{\circ} \mathrm{C}$. By plotting and calculating all data using the same approach as for the reaction between 1.0 $\mathrm{mM}$ of BNPP and $1.0 \mathrm{mM}$ of ZrK $2: 2,{ }^{[13]}$ (for which the concentration of both $12 \mathrm{a}$ and $\mathrm{I} 2 \mathrm{~b}$ was too low to be detected in the ${ }^{1} \mathrm{H}$ spectra), the rate constants could be calculated. By taking into account only 12a a rate constant of $8.95( \pm 0.22) \times 10^{-5} \mathrm{~s}^{-1}$ was calculated, while a value of $8.92( \pm 0.23) \times 10^{-5} \mathrm{~s}^{-1}$ was obtained when both $\operatorname{In} 2 \mathrm{a}$ and $12 \mathrm{~b}$ were taken into account. When both $12 \mathrm{a}$ and $\mathrm{I} 2 \mathrm{~b}$ were omitted a rate constant of $9.17( \pm 0.16) \times$ $10^{-5} \mathrm{~s}^{-1}$ was obtained. These rate constant values are almost identical, suggesting that $12 \mathrm{a}$ and $12 \mathrm{~b}$ do not influence the calculation of the rate constants. An explanation for this fact is that the percentages of the $12 \mathrm{a}$ and/or $12 \mathrm{~b}$ are low in comparison with the sum of the percentages of BNPP and NP during the hydrolytic reaction (Figure 4). In addition, from Figure S2 it can be seen that the plot showing $\ln [\mathrm{BNPP}]$ as a function of reaction time is well linear when $12 \mathrm{a}$ and $12 \mathrm{~b}$ were taken into account, meaning that BNPP hydrolysis can be described using first-order reaction kinetics.

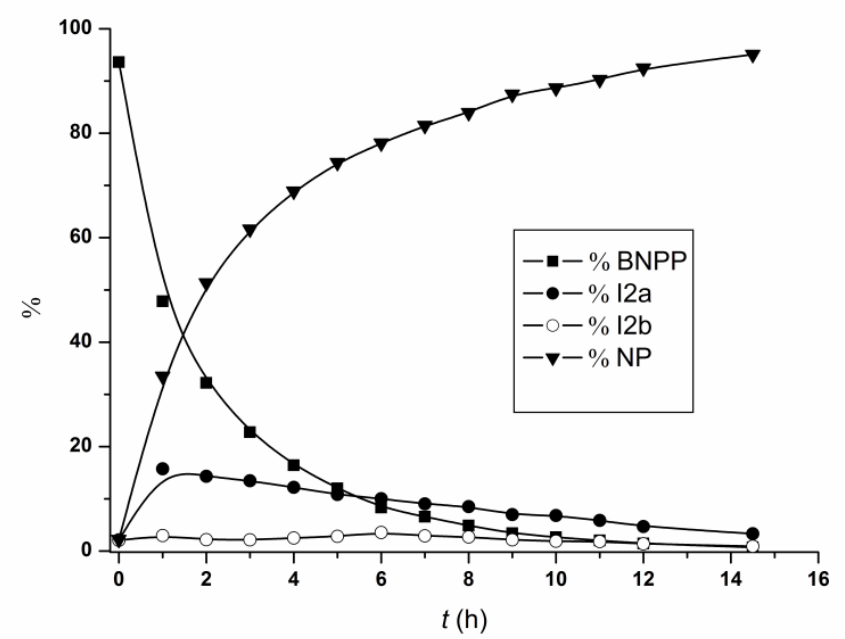

Figure 4. Percentage of BNPP, NP, $12 \mathrm{a}, 12 \mathrm{~b}$ as a function of reaction time for the reaction between $6.0 \mathrm{mM}$ of BNPP and $6.0 \mathrm{mM}$ of ZrK 2:2 at pD 6.4 and $60{ }^{\circ} \mathrm{C}$.

The broad lineshape of the $12 \mathrm{~b}$ and NPP resonances in the spectra of the BNPP/ZrK2:2 mixture indicates that these species are in slow exchange with other species with respect to ${ }^{1} \mathrm{H}$ chemical shift time scale. The slow exchange between NPP, 12a and $\mathrm{I} 2 \mathrm{~b}$ during the hydrolysis of both BNPP and NPP, promoted by ZrK 2:2, was investigated by 2D EXSY NMR. Figures $5 \mathrm{a}$ and 
5b present the EXSY spectra of the two samples, showing identical types of exchange cross-peaks between $12 \mathrm{a}$ and NPP, NPP and $12 \mathrm{~b}$, and between $12 \mathrm{a}$ and $12 \mathrm{~b}$ in both samples. This result also proves that the hydrolysis of BNPP involves as an intermediate reaction step the formation of NPP which is in equilibrium with $\mathrm{I} 2 \mathrm{a}$ and $\mathrm{I} 2 \mathrm{~b}$.

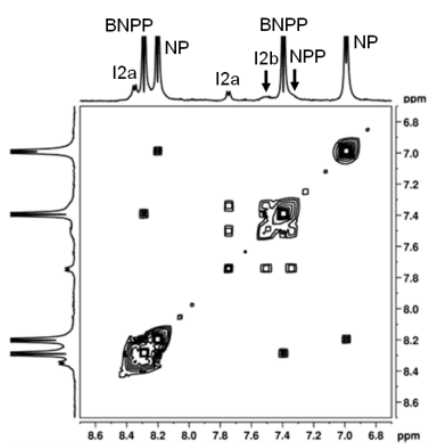

a

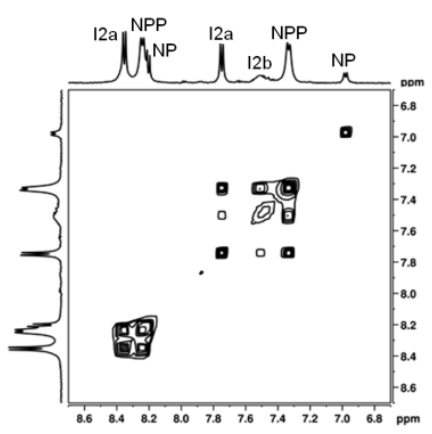

b
Figure 5. ${ }^{1} \mathrm{H}$ EXSY spectra of the hydrolysis reaction (a) between $3.0 \mathrm{mM}$ of BNPP in the presence of $3.0 \mathrm{mM}$ of ZrK 2:2 after $4 \mathrm{~h}$ and (b) between $3.0 \mathrm{mM}$ of NPP in the presence of $3.0 \mathrm{mM}$ of ZrK 2:2 after 20 minutes at pD 6.4 and 60 ${ }^{\circ} \mathrm{C}$.

In a further step the ${ }^{31} \mathrm{P}$ spectra were measured with the aim to prove the formation of the non-protonated intermediate 13 and the final end product $\mathrm{P}$. The ${ }^{31} \mathrm{P}$ spectrum of the mixture of 3.0 $\mathrm{mM}$ of BNPP and $3.0 \mathrm{mM}$ of ZrK 2:2 (Figure 6a) shows four intense signals originating from BNPP (-11.23 ppm), ZrK 2:2 ($13.80 \mathrm{ppm})$ and ZrK 1:2 (-14.85 and $-14.94 \mathrm{ppm})$, which is also present at this POM concentration. ${ }^{[13]}$

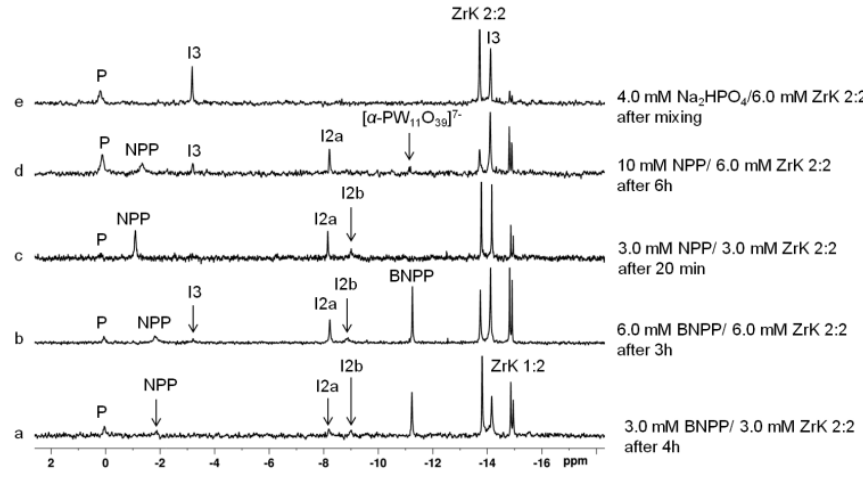

Figure 6. ${ }^{31} \mathrm{P}$ NMR of the hydrolysis reaction between $3.0 \mathrm{mM}$ of BNPP in the presence of $3.0 \mathrm{mM}$ of ZrK $2: 2$ and $3.0 \mathrm{mM}$ of NPP in the presence of $3.0 \mathrm{mM}$ of $\mathrm{ZrK} 2: 2$ at different time intervals at $\mathrm{pD} 6.4$ and $60{ }^{\circ} \mathrm{C}$. The ${ }^{31} \mathrm{P}$ spectra of $6.0 \mathrm{mM}$ of BNPP in the presence of $6.0 \mathrm{mM}$ of ZrK $2: 2$, of $10.0 \mathrm{mM}$ of NPP in the presence of $6.0 \mathrm{mM}$ of $\mathrm{ZrK} 2: 2$ and of $4.0 \mathrm{mM}$ of $\mathrm{Na}_{2} \mathrm{HPO}_{4}$ in the presence of $6.0 \mathrm{mM}$ of $\mathrm{ZrK} \mathrm{2:2}$ have been added for comparison $\left(400 \mathrm{MHz}, \mathrm{D}_{2} \mathrm{O}, 293 \mathrm{~K}\right.$, $\mathrm{NS}=256,25 \% \mathrm{H}_{3} \mathrm{PO}_{4}$ ).

The peak at 0 ppm clearly evidences the formation of phosphate during the hydrolysis. In addition to these well identifiable resonances the ${ }^{31} \mathrm{P}$ spectrum shows three low intensity signals at $-1.86 \mathrm{ppm},-8.18$ and $-8.99 \mathrm{ppm}$. The first peak $(-1.86 \mathrm{ppm})$ is most likely the peak of NPP, which is somewhat shifted due to a slight change of the $\mathrm{pD}$ of the solution that could occur as a result of the release of phosphate. The next two peaks ( -8.18 and $-8.99 \mathrm{ppm}$ ) originate from the organic part of intermediates $12 \mathrm{a}$ and $\mathrm{I} 2 \mathrm{~b}$ respectively, while the signal at $-14.16 \mathrm{ppm}$ was assigned to the ${ }^{31} \mathrm{P}$ atoms from the POM part of these intermediates. To improve the sensitivity and for better detection of the intermediates we recorded $\mathrm{a}^{31} \mathrm{P}$ spectrum of a mixture of $6.0 \mathrm{mM} \mathrm{BNPP}$ and $6.0 \mathrm{mM} \mathrm{ZrK} \mathrm{2:2,}$ where the signals of the three intermediates are clearly visible (Figure 6b). In this spectrum, the peak at $-2.79 \mathrm{ppm}$ was assigned to 13. The assignment of the intermediates was performed by comparison with the signals observed in the ${ }^{31} \mathrm{P}$ spectra of a mixture of $3.0 \mathrm{mM}$ of NPP and $3.0 \mathrm{mM}$ of ZrK 2:2 (Figure $6 \mathrm{c}$ ), a mixture of $10.0 \mathrm{mM}$ of NPP and $6.0 \mathrm{mM}$ of ZrK 2:2 (Figure 6d) and also a mixture of $4.0 \mathrm{mM}$ of $\mathrm{Na}_{2} \mathrm{HPO}_{4}$ and 6.0 $\mathrm{mM}$ of ZrK 2:2 (Figure 6e), where the only expected intermediate is 13. Thus the peak at $-1.86 \mathrm{ppm}$ was attributed to $\mathrm{NPP}$, the peak at $-2.79 \mathrm{ppm}$, which was visible in Figure $6 \mathrm{~b}$ but invisible in Figure $6 a$ due to low intensity, originates from 13 , the peak at $-8.18 \mathrm{ppm}$ was assigned to $12 \mathrm{a}$, while the broader resonance at $-8.99 \mathrm{ppm}$ resulted from the presence of $\mathrm{I} 2 \mathrm{~b}$. More details on the comparative experiments are given in the supporting information (Figures S3, S4 and S5).

Further evidence for the presence of intermediates is given by the ${ }^{1} \mathrm{H}$ DOSY spectra of the BNPP/ZrK2:2 mixture recorded during the course of the reaction (Figure 7a). The spectrum shows three main species, characterized by different diffusion coefficients. The faster diffusing species (8.2 ppm and $7.0 \mathrm{ppm})$ with a diffusion coefficient of $6.46 \times 10^{-10} \mathrm{~m}^{2} / \mathrm{s}$ was assigned to $\mathrm{NP}$, a product of the hydrolytic reaction (Scheme 1 ). The second species, represented by NMR signals at $7.4 \mathrm{ppm}$ and $8.3 \mathrm{ppm}$ with diffusion coefficient of $4.23 \times 10^{-10} \mathrm{~m}^{2} / \mathrm{s}$ was assigned to BNPP. The slowest species (7.75 ppm and $8.35 \mathrm{ppm})$ has a diffusion coefficient of $2.09 \times 10^{-10} \mathrm{~m}^{2} / \mathrm{s}$, which is significantly lower than that of BNPP. This indicates that in this third species, NPP is interacting with the ZrK 2:2, and thus should represent one of the intermediates, most likely $12 \mathrm{a}$ as evidenced also by the ${ }^{1} \mathrm{H}$ and ${ }^{31} \mathrm{P}$ spectra. Unfortunately the detection of the $12 \mathrm{~b}$ and NPP was not possible in the DOSY spectra due to the very low intensity of their signals.

The ${ }^{1} \mathrm{H}$ DOSY spectra of NPP/ZrK 2:2 mixture (Figure $7 \mathrm{~b}$ ) also show the presence of three species. The lowest diffusion coefficient measured for this sample corresponding to the peaks at $7.75 \mathrm{ppm}$ and $8.35 \mathrm{ppm}$, has exactly the same value $(2.09 \times$ $10^{-10} \mathrm{~m}^{2} / \mathrm{s}$ ) as the one for $12 \mathrm{a}$ measured in the BNPP/ZrK 2:2 mixture. The second component with diffusion coefficient of 4.37 $\times 10^{-10} \mathrm{~m}^{2} / \mathrm{s}$ is assigned to NPP (7.34 ppm and $\left.8.23 \mathrm{ppm}\right)$. The third component, assigned to the reaction product NP has again exactly the same diffusion coefficient as the one measured for the BNPP/ZrK mixture. These results confirm that BNPP hydrolysis involves transient formation of NPP whose mechanism of ZrK promoted hydrolysis is identical with those of the pure NPP, as in both cases the same types of intermediates were detected.

Unfortunately the $1 \mathrm{D}{ }^{1} \mathrm{H}$ and ${ }^{31} \mathrm{P}$ (Figures 3 and 6) as well as the $2 \mathrm{D}{ }^{1} \mathrm{H}$ NMR experiments (Figures 5 and 7 ) do not give clear evidence for the catalytically active POM species (ZrK 2:2 or ZrK 1:1) responsible for the hydrolysis of BNPP and NPP. Although to the best of our knowledge the monomeric ZrK 1:1 has not been isolated and experimentally observed so far, the possibility of condition dependent fast exchange between the dimer ZrK 2:2 and monomer ZrK 1:1 species in pure aqueous solution should be taken into account. If this is the case one averaged signal will be observed for these two species in the ${ }^{31} \mathrm{P}$ spectrum and the chemical shift of the observed signal will then represent 
a population weighted average of the chemical shifts of the two species, meaning that their discrimination is not possible. The existence of dimer-monomer equilibrium, assisted by the acid protons of the POMs has been already suggested, but not experimentally proven for two $\mathrm{Zr}^{\mathrm{IV}}$ Keggin-type POMs: (n$\left.\mathrm{Bu}_{4} \mathrm{~N}\right)_{7} \mathrm{H}\left[\left\{\mathrm{PW}_{11} \mathrm{O}_{39} \mathrm{Zr}-(\mu-\mathrm{OH})\right\}_{2}\right]$ and $\left(\mathrm{n}-\mathrm{Bu}_{4} \mathrm{~N}\right)_{8}\left[\left\{\mathrm{PW}_{11} \mathrm{O}_{39} \mathrm{Zr}(\mu-\right.\right.$ $\mathrm{OH})\}_{2}$ ] in MeCN solution in the presence of increasing amounts of water. ${ }^{[20]}$ The experimental proof of the existence of ZrK 1:1 species is indeed not straightforward. Its isolation from solution is not possible since it tends to dimerize during the crystallization process. On the other hand, its detection by ${ }^{31} \mathrm{P} N M R$ in aqueous solution is hampered by its fast exchange with ZrK 2:2 (resulting in one averaged signal) and the conversion to ZrK 1:2 at higher concentrations needed for the measurement of ${ }^{31} \mathrm{P}$ spectra with good signal-to-noise ratio at a reasonable experimental time. ${ }^{[13]}$

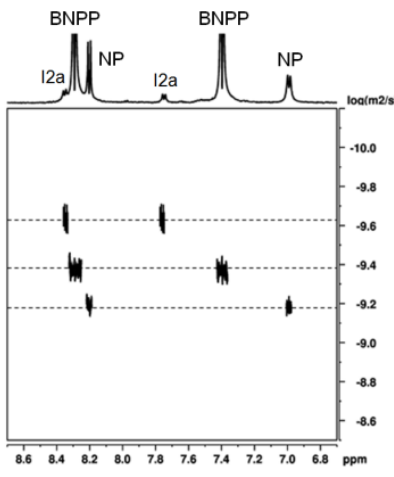

a

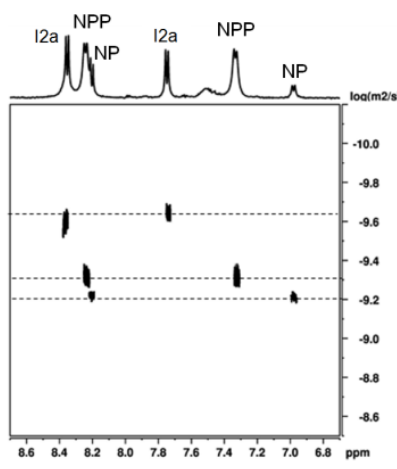

b
Figure 7. ${ }^{1} \mathrm{H}$ DOSY spectra of (a) $3.0 \mathrm{mM}$ of BNPP in the presence of $3.0 \mathrm{mM}$ of ZrK 2:2 after $4 \mathrm{~h}$ and (b) $3.0 \mathrm{mM}$ of NPP in the presence of $3.0 \mathrm{mM}$ of ZrK 2:2 after $20 \mathrm{~min}$ at $\mathrm{pD} 6.4$ and $60^{\circ} \mathrm{C}$.

With the aim to experimentally prove the presence of the monomeric species we first monitored the $\mathrm{pD}$ dependence of the ${ }^{31} \mathrm{P}$ signal chemical shifts of a $1.0 \mathrm{mM}$ solution of ZrK 2:2. The results are presented in Figure 8.

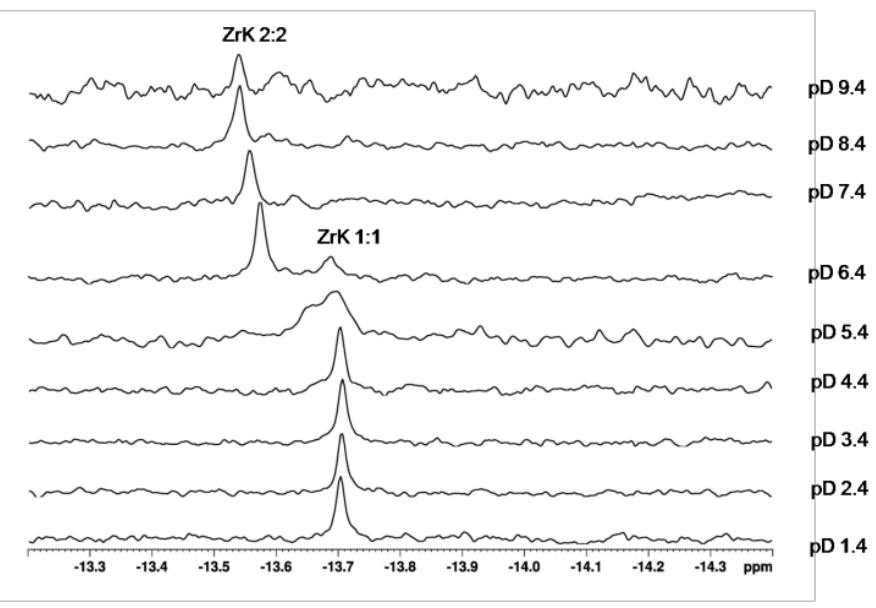

Figure 8. ${ }^{31} \mathrm{P}$ spectra of a $1.0 \mathrm{mM}$ solution of $\mathrm{ZrK} 2: 2$ at various $\mathrm{pD}$ values.

As can be seen from Figure 8 , at the three lowest $\mathrm{pD}$ values (1.4 to 3.4 ) only one signal at $-13.70 \mathrm{ppm}$ is observed and its chemical shift remains constant upon the increase of the $\mathrm{pD}$ from 1.4 up to 3.4. The constant chemical shift is an indication for the presence of only one species within this $\mathrm{pD}$ range, which we assume to be the monomeric ZrK 1:1. At further increase of the $\mathrm{pD}$ a down-field shift accompanied by signal broadening is observed. At the pD value of 5.4 two broad and partially overlapping peaks are observed in the spectrum. This spectral pattern reveals the existence of two species, exchanging at intermediate rate with respect to the ${ }^{31} \mathrm{P}$ chemical shift time scale, and clearly confirms the presence of ZrK 2:2 and ZrK 1:1 in pure aqueous solution. Upon further increase of pD from 5.4 up to 8.4 , both signals shift further down-field. In parallel to this, the down-field peak assigned to ZrK 2:2, sharpens and increases in intensity, while the intensity of the upfield signal, assigned to ZrK 1:1, decreases and almost disappears. These observations indicate the shift of the dimer/monomer equilibrium from ZrK 1:1, the dominant species in more acidic solutions to ZrK 2:2, the more favorable species in more basic solutions. At the two highest $\mathrm{pD}$ values only one signal with constant chemical shift of $-13.54 \mathrm{ppm}$ is observed, which indicates the presence of ZrK 2:2 only.

Aiming to give additional experimental support to our interpretation of the $\mathrm{pD}$ dependence of ZrK speciation in aqueous solution, we measured ${ }^{31} \mathrm{P}$ DOSY spectra of a mixture of $3.0 \mathrm{mM} \mathrm{ZrK} \mathrm{2:2} \mathrm{and} 3.0 \mathrm{mM} Z \mathrm{ZrK} 1: 2$ in $\mathrm{D}_{2} \mathrm{O}$ at pD 6.4. For comparison ${ }^{31} \mathrm{P}$ DOSY spectra of $3.0 \mathrm{mM}$ solutions of ZrK 2:2 at pD 1.4 and 6.4 were also recorded. The $3.0 \mathrm{mM}$ concentration was chosen because at this concentration the conversion of ZrK $2: 2$ to ZrK $1: 2$ is still relatively slow at room temperature ${ }^{[13]} \mathrm{At}$ this concentration one ${ }^{31} \mathrm{P}$ DOSY measurement took 9:30 $\mathrm{h}$ to achieve a signal-to-noise ratio good enough to ensure a reliable measurement of the diffusion coefficients. The measurements were performed at a temperature of $10^{\circ} \mathrm{C}$ in order to completely avoid the conversion of ZrK 2:2 to ZrK 1:2 during the timeframe of the DOSY experiments, which could influence the measured diffusion coefficients. In addition $1 \mathrm{D}{ }^{31} \mathrm{P}$ spectra were recorded before and after each ${ }^{31} \mathrm{P}$ DOSY experiment in order to check for possible 2:2 to $1: 2$ conversion, and no changes in signal intensities were detected at this concentration at $10^{\circ} \mathrm{C}$. Figure 9 shows the ${ }^{31} \mathrm{P}$ DOSY spectrum of a mixture of $3.0 \mathrm{mM} \mathrm{ZrK} \mathrm{2:2}$ and $3.0 \mathrm{mM}$ ZrK $1: 2$ in $\mathrm{D}_{2} \mathrm{O}$ at pD 6.4 and $10^{\circ} \mathrm{C}$.

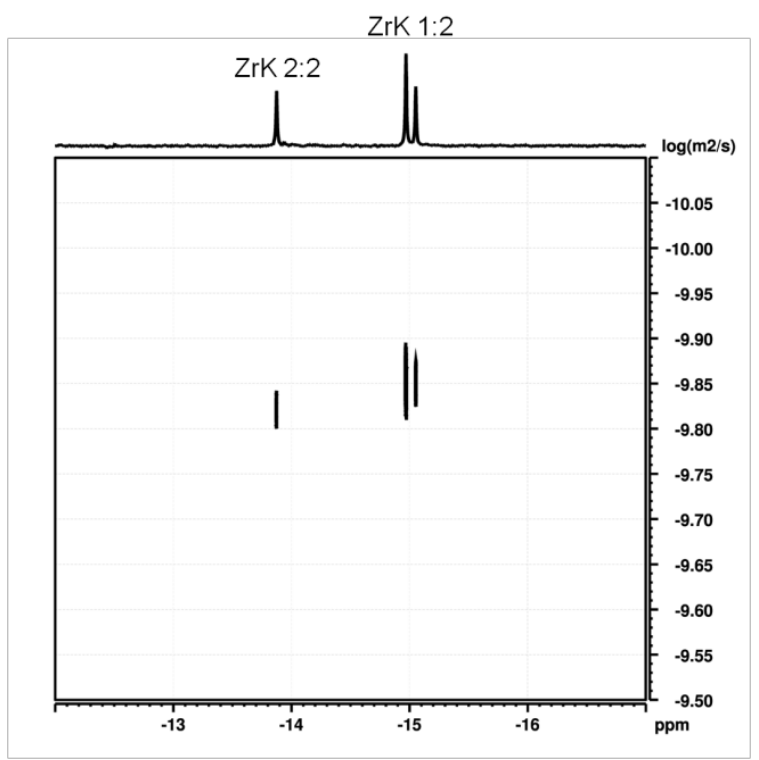

Figure 9. ${ }^{31} \mathrm{P}$ DOSY spectrum of a mixture of $3.0 \mathrm{mM} \mathrm{ZrK} \mathrm{2:2} \mathrm{and} 3.0 \mathrm{mM} \mathrm{ZrK}$ $1: 2$ in $\mathrm{D}_{2} \mathrm{O}$ at $\mathrm{pD} 6.4$ and $10^{\circ} \mathrm{C}$. 
The ${ }^{31} \mathrm{P}$ DOSY spectrum in Figure 9 shows that the diffusion coefficient of $1.40 \times 10^{-10} \mathrm{~m}^{2} / \mathrm{s}\left( \pm 1.18 \times 10^{-12}\right)$ corresponding to the peaks at -14.85 and $-14.94 \mathrm{ppm}$, assigned to ZrK 1:2, is lower as compared to the value of $1.49 \times 10^{-10} \mathrm{~m}^{2} / \mathrm{s}\left( \pm 7.14 \times 10^{-13}\right)$ measured for the peak at $-13.80 \mathrm{ppm}$ assigned to ZrK 2:2. The best fit of the diffusion attenuation profiles of the signals with a variant of Stejskal-Tanner equation adapted to the particular pulse sequence used is presented in Figure S6. However if at these experimental conditions ZrK 2:2 and ZrK 1:2 were the only species present in the solution the diffusion coefficient of ZrK 2:2 should be lower than the diffusion coefficient of ZrK 1:2, because of its larger size. The results from DOSY measurements could be explained if we assume that ZrK 2:2 is in a fast equilibrium with a small amount of ZrK 1:1. In that case the measured diffusion coefficient of the species represented by the signal at $-13.80 \mathrm{ppm}$ will be a population weighted average of the diffusion coefficients of ZrK 2:2 and ZrK 1:1. Since the size of ZrK 1:1 is much smaller and hence its diffusion coefficient is higher, the exchange of the two species results in an overall higher diffusion coefficient as compared to that for ZrK 1:2. A diffusion coefficient of $2.34 \times 10^{-10} \mathrm{~m}^{2} / \mathrm{s}\left( \pm 2.81 \times 10^{-12}\right)$ was determined for ZrK 1:1 from the ${ }^{31} \mathrm{P}$ DOSY spectrum of a $3.0 \mathrm{mM}$ solution of $\mathrm{ZrK} 2: 2$ at $10{ }^{\circ} \mathrm{C}$ and $\mathrm{pD} 1.4$, at which it is the only species present in the solution (Figure S7). These results undoubtedly prove the existence of $Z$ rK $1: 1$ in pure aqueous solutions of ZrK 2:2 at the reaction conditions.

To further strengthen these findings and to shed more light on the mechanism of BNPP hydrolysis at a molecular level, DFT calculations were performed.

\section{DFT modeling of the phospho(di)ester binding modes to $\mathrm{Zr}^{\mathrm{IV}}$-substituted Keggin POMs}

In order to identify the hydrolytically active POM and to elucidate the molecular nature of $11,12 \mathrm{a}, 12 \mathrm{~b}$ and 13 intermediates the coordination properties of BNPP', NPP ${ }^{2-}$ and $\mathrm{H}_{2} \mathrm{PO}_{4}^{-}(\mathrm{P})$ anions to the ZrK POM species were investigated. As reported earlier and as observed in our NMR studies, the ZrK 2:2 and ZrK 1:2 species (Figure 2) readily interconvert in the reaction mixture and the amount of the latter increases with the increase of the BNPP concentration. ${ }^{[13]}$ The $\mathrm{Zr}$ atom in the ZrK 1:2 is, however, coordinatively saturated and hardly accessible for the bulky BNPP and NPP ligands, as it is sandwiched by the two Keggin moieties. Therefore, substrate coordination to ZrK $1: 2$ is not expected and this case was not examined here. Moreover, computation of the free energy change related with the formation of ZrK 1:2 from its parent compound, ZrK 2:2, is hampered because the reaction stoichiometry presumes liberation of a $\mathrm{Zr}^{\mathrm{IV}}$ cation whose aqueous speciation in the reaction conditions first has to be elucidated. Thus, our efforts were focused on modeling the most feasible coordination compounds of ZrK 2:2 and ZrK 1:1 POMs.

To find the most stable complexes which might be relevant for the hydrolytic process, different binding modes of the substrates to the POMs were modeled and the corresponding free energies of formation were assessed by assuming reactions of substrate$\mathrm{H}_{2} \mathrm{O}$ ligand exchange. A schematic presentation of the considered coordination modes and the associated free energies of formation are given in Figure 10 (optimized structures, in Cartesian coordinates, and detailed energy data are given in the SI, Table S1). As determined by X-ray analysis, ${ }^{[15 b]}$ there are two coordinated $\mathrm{H}_{2} \mathrm{O}$ molecules in the [ $\{\alpha-$ $\left.\left.\mathrm{PW}_{11} \mathrm{O}_{39} \mathrm{Zr}(\mu-\mathrm{OH})\left(\mathrm{H}_{2} \mathrm{O}\right)\right\}_{2}\right]^{8-}$ dimer, one to each $\mathrm{Zr}$ center, located trans to each other with respect to the $\{\mathrm{Zr}-\mu-\mathrm{OH}\}_{2}$-ring (Figure 2a). Both $\mathrm{H}_{2} \mathrm{O}$ ligands form $\mathrm{H}$-bonds with bridging $\mathrm{Zr}-\mathrm{O}-\mathrm{W}$ oxygen atoms of the POM skeleton. This conformation will be denoted further as trans-ZrK 2:2. Monodentate coordination of both BNPP and NPP phosphate oxygens to a $\mathrm{Zr}$ atom of transZrK 2:2 was calculated to be endergonic by 17.7 and $17.8 \mathrm{kcal}$ $\mathrm{mol}^{-1}$ respectively. Due to the low conformational flexibility of the $\left[\left\{\alpha-\mathrm{PW}_{11} \mathrm{O}_{39} \mathrm{Zr}(\mu-\mathrm{OH})\left(\mathrm{H}_{2} \mathrm{O}\right)\right\}_{2}\right]^{8-}$ framework substitution of one $\mathrm{H}_{2} \mathrm{O}$ in trans-ZrK 2:2 by the bulky BNPP or NPP ligand leads to increased steric hindrance. Moreover, repulsive interactions between the negatively charged substrate $\mathrm{PO}_{4}$ group and the Keggin fragments (which are now in close proximity) additionally destabilize the resulting complexes. Significantly lower, but still positive free energies of formation are obtained (13.8 and 5.5

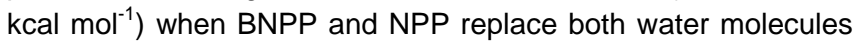
of the $\mathrm{POM}$ and the $\mathrm{PO}_{4}$ group acts as a bidentate ligand bridging the two neighboring $\mathrm{Zr}$ atoms (Figure 10). In these complexes the ZrK 2:2 fragment has adopted a cis conformation where the Keggin moieties are angled towards the $\mathrm{Zr}-(\mu-\mathrm{OH})_{2}-\mathrm{Zr}$ junction. One may assume that interconversion from trans to cis ZrK 2:2 conformation could independently take place in solution. To address this issue a complex (cis-ZrK 2:2) where both water molecules occupy the same side of the $\{\mathrm{Zr}-\mu-\mathrm{OH}\}_{2}$-plane was modeled. The cis-ZrK 2:2 conformer was found to be $8.5 \mathrm{kcal}$ $\mathrm{mol}^{-1}$ higher in energy than trans-ZrK $2: 2$, suggesting that the equilibrium is largely shifted to the trans form. The higher energy of the cis arrangement is primarily caused by the rupture of one strong $\mathrm{H}$-bond formed by a $\mathrm{H}_{2} \mathrm{O}$ proton and a bridging $\mathrm{Zr}-\mathrm{O}-\mathrm{W}$ oxygen atom. Although the cis-ZrK 2:2 conformer is less stable, its $\mathrm{Zr}$ centers are comparatively less sterically hindered at the $\mathrm{H}_{2} \mathrm{O}$ side. Hence, one may expect that coordination of BNPP and NPP ligands to the cis form should be more likely than to trans-ZrK 2:2. According to the calculations monodentate coordination of BNPP to cis-ZrK 2:2 is an endergonic process requiring $8.7 \mathrm{kcal} \mathrm{mol}^{-1}$. As compared to the initial trans-ZrK 2:2 + BNPP reactants, however, the energy requirement is $17.2 \mathrm{kcal}$ $\mathrm{mol}^{-1}$, virtually the same as for monodentate BNPP binding to trans-ZrK 2:2 (17.7 kcal mol $\left.{ }^{-1}\right)$. In the case of NPP, monodentate coordination in cis position with respect to the remaining $\mathrm{H}_{2} \mathrm{O}$ is more stable by $7.7 \mathrm{kcal} \mathrm{mol}^{-1}$ as compared to the corresponding trans arrangement. However, the free energy of the cis complex, $10.1 \mathrm{kcal} \mathrm{mol}^{-1}$, is still rather high when compared to the initial reactants (free NPP and trans-ZrK 2:2). Thus, based on these results we may conclude that neither monodentate nor bidentate bridging BNPP/NPP coordination to ZrK 2:2 leads to the formation of thermodynamically stable products.

The reaction of monomerization ZrK 2:2 2 ZrK 1:1 has recently been examined by means of DFT. ${ }^{[21]}$ In that study the authors reported the reaction to be endothermic by $23.6 \mathrm{kcal}$ $\mathrm{mol}^{-1}$. Their calculations, however, neglected the entropy change associated with this process. Taking the entropy contribution into account the calculated aqueous phase free energy change for this monomerization reaction is only $3.4 \mathrm{kcal} \mathrm{mol}^{-1}$ (Figure 10). This result strongly suggests that the monomeric ZrK 1:1 species should be present in aqueous solution even at near neutral $\mathrm{pH}$, in full agreement with the experimental findings. As shown in Figure 8, decreasing the pH causes a shift of the ZrK $2: 2 \leftrightarrow 2$ ZrK 1:1 equilibrium towards ZrK 1:1. This is most probably due to protonation of the $\mathrm{Zr}-\mathrm{OH}$ group, obstructing its 
ability to act as bridging ligand without further reorganization e.g. proton transfer. Conversely, alkaline solutions promote dimerization of the $\mathrm{POM}-\mathrm{Zr}-\mathrm{OH}$ moieties via $\mu-\mathrm{OH}$ bridges. ${ }^{[21]}$

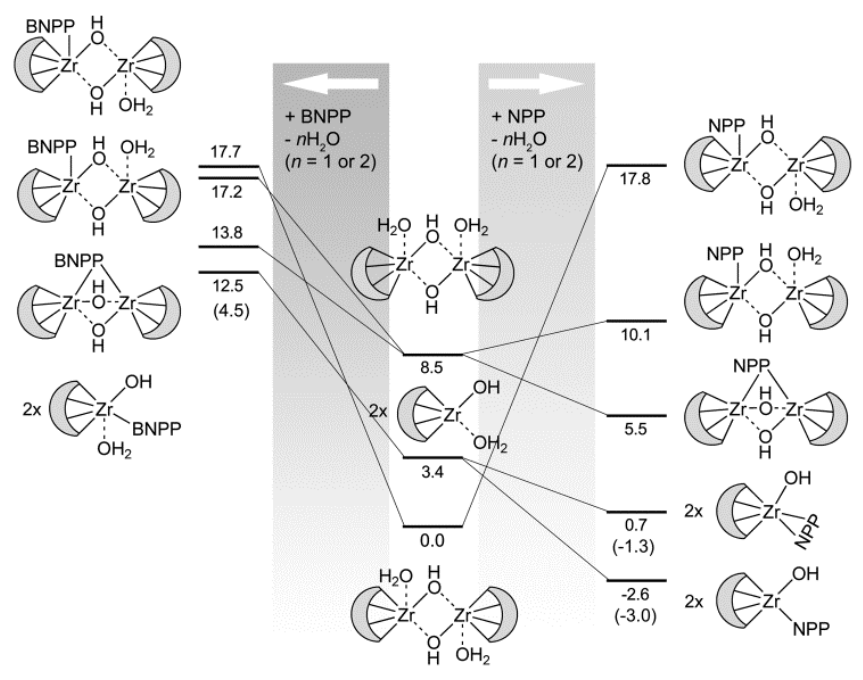

Figure 10. Binding modes of BNPP and NPP to ZrK 2:2 and ZrK 1:1. All energy values $\left(\mathrm{kcal} \mathrm{mol}^{-1}\right.$ ) are relative to the initial reactants (free BNPP or NPP, trans-ZrK 2:2). Note that both ZrK 1:1 species, formed upon ZrK 2:2 $\rightarrow 2$ ZrK 1:1 monomerization, are allowed to interact with a substrate. Values in parentheses correspond to the single process $L+Z$ rK 1:1 $\rightarrow \quad-Z r K ~ 1: 1+\mathrm{H}_{2} \mathrm{O}$ ( $L=$ BNPP, NPP).

Replacement of a $\mathrm{H}_{2} \mathrm{O}$ ligand by a BNPP anion in ZrK 1:1 results in a $\left[\mathrm{PW}_{11} \mathrm{O}_{39} \mathrm{Zr}(\mathrm{OH})(\mathrm{BNPP})\right]^{5-}$ species, where the substrate is monodentate coordinated to the $\mathrm{Zr}$ center via a phosphate oxygen. A similar complex, $\left[\mathrm{PW}_{11} \mathrm{O}_{39} \mathrm{Zr}(\mathrm{OH})\left(\mathrm{H}_{2} \mathrm{O}\right)(\mathrm{BNPP})\right]^{5-}$, only slightly more stable (by 0.1 $\left.\mathrm{kcal} \mathrm{mol}^{-1}\right)$, is formed upon BNPP addition without water release. The latter complex is higher in energy than the reactants ( $\mathrm{ZrK}$ $1: 1$ and BNPP) by $4.5 \mathrm{kcal} \mathrm{mol}^{-1}$ (Figure 10). Starting from transZrK 2:2 (and assuming that both ZrK 1:1 species coordinate a BNPP anion) the formation energy becomes $12.5 \mathrm{kcal} \mathrm{mol}^{-1}$, which is comparable to the formation energy of the bridging BNPP complex with ZrK 2:2 (13.8 $\mathrm{kcal} \mathrm{mol}^{-1}$, Figure 10). Any attempt to locate a monomeric compound where BNPP acts as a bidentate ligand was unsuccessful, in all cases the optimizations converged to a monodentate complex.

Substitution of $\mathrm{a}_{2} \mathrm{O}$ ligand by NPP in ZrK 1:1 may give rise to either bidentate or monodentate NPP coordination. The associated formation energies are slightly negative, $-1.3 \mathrm{kcal}$ $\mathrm{mol}^{-1}$ (bidentate) and $-3.0 \mathrm{kcal} \mathrm{mol}{ }^{-1}$ (monodentate) respectively. Starting from trans-ZrK 2:2 the reaction energies become 0.7 and $-2.6 \mathrm{kcal} \mathrm{mol}^{-1}$. Obviously, phospho(di)ester substrate binding is more likely (or at least equally likely, as found for BNPP) to occur at a monomeric Zr-substituted Keggin POM than for the initial dimer compound, ZrK 2:2.This points to ZrK 1:1 as the major player in promoting the hydrolytic phosphoester cleavage.

In a next step, we have investigated the effect of (i) the number of coordinated $\mathrm{H}_{2} \mathrm{O}$ molecules and (ii) the protonation state of the $\mathrm{Zr}-\mathrm{OH}$ nucleophile, on the stability of the ZrK 1:1 complexes with BNPP and NPP. For this purpose, two series of compounds were considered. The first series consists of $\mathrm{POM}$ $\mathrm{Zr}\left(\mathrm{H}_{2} \mathrm{O}\right)_{\mathrm{n}}(\mathrm{n}=2,3)$, POM- $\mathrm{Zr}(\mathrm{BNPP})\left(\mathrm{H}_{2} \mathrm{O}\right)_{\mathrm{n}}(\mathrm{n}=1,2)$, POM$\mathrm{Zr}(\mathrm{NPP}$-bidentate $)\left(\mathrm{H}_{2} \mathrm{O}\right)$ and POM-Zr(NPP-monodentate $)\left(\mathrm{H}_{2} \mathrm{O}\right)_{n}$
( $n=1,2$ ), while the second series is composed of the corresponding conjugated bases obtained from deprotonation of an $\mathrm{H}_{2} \mathrm{O}$ ligand: $\mathrm{POM}-\mathrm{Zr}(\mathrm{OH})\left(\mathrm{H}_{2} \mathrm{O}\right)_{\mathrm{n}} \quad(\mathrm{n}=1,2)$, POM$\mathrm{Zr}(\mathrm{BNPP})(\mathrm{OH})\left(\mathrm{H}_{2} \mathrm{O}\right)_{\mathrm{n}}(\mathrm{n}=0,1), \mathrm{POM}-\mathrm{Zr}(\mathrm{NPP}$-bidentate $)(\mathrm{OH})$ and POM-Zr(NPP-monodentate) $(\mathrm{OH})\left(\mathrm{H}_{2} \mathrm{O}\right)_{n}(n=0,1)$. The relative stability of the compounds within each of the series is estimated by using the free energies of $\mathrm{POM}-\mathrm{Zr}\left(\mathrm{H}_{2} \mathrm{O}\right)_{2}$ or POM$\mathrm{Zr}(\mathrm{OH})\left(\mathrm{H}_{2} \mathrm{O}\right)$ as a reference. The results are plotted in Figure 11. Armed with these data it is, in principle, possible to compute the $\mathrm{Zr}-\mathrm{OH}_{2} \quad \mathrm{pK}_{\mathrm{a}}$ value for each of the complexes in the first series. An accurate prediction of absolute $p K_{\mathrm{a}}$ values, however, requires a very accurate estimation of the hydration free energies. For highly charged species this is not realizable when making use of continuum solvation models, such as COSMO. A qualitative estimate of the acidity of the $\mathrm{Zr}-\mathrm{OH}_{2}$ protons may instead be obtained from the relative $p K_{a}$ values $\left(\Delta p K_{a}\right)$ which should be more reliable because of error cancelation. These data are also provided in Figure 11.

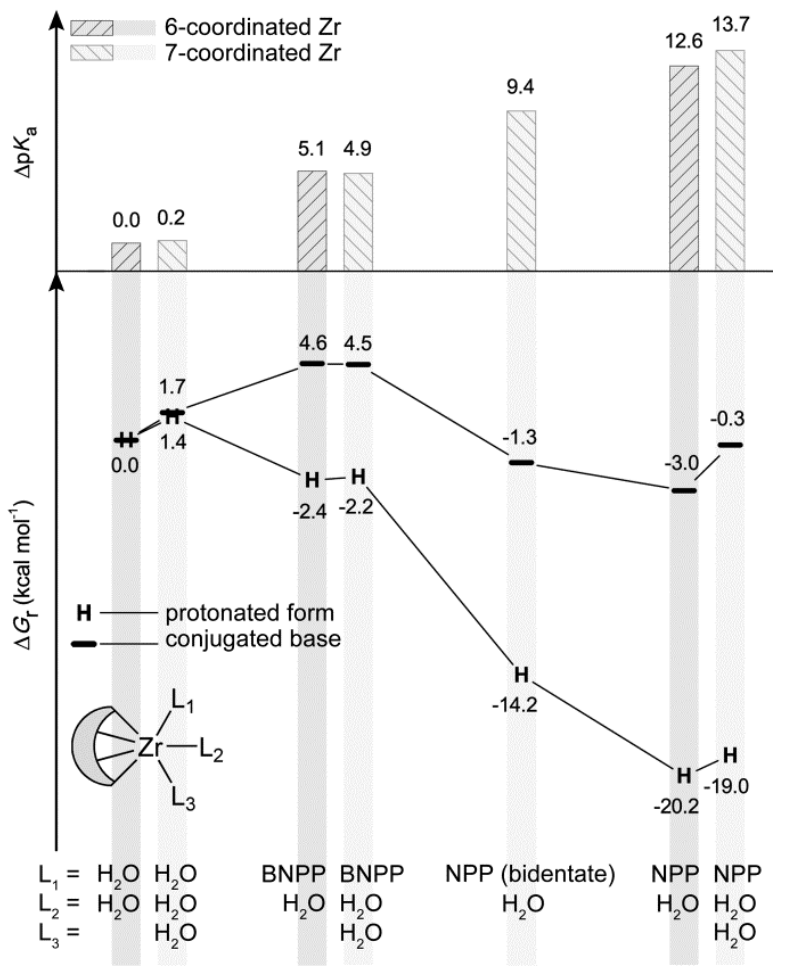

Figure 11. Relative free energy $\left(\mathrm{kcal} \mathrm{mol}^{-1}\right)$ and relative $\mathrm{p} K_{\mathrm{a}}$ values of the $\mathrm{ZrK}$ 1:1 based complexes of $\mathrm{H}_{2} \mathrm{O}$, BNPP and NPP. The free energy difference between the two energy curves is related to the relative $\mathrm{p} K_{\mathrm{a}}$ values by the factor $1 /[R T \ln (10)]$.

As may be seen from Figure 11, increasing the coordination number of $\mathrm{Zr}$ from 6 to 7 by addition of a $\mathrm{H}_{2} \mathrm{O}$ molecule has a minor effect on all complex stabilities. This suggests that in water solution the monomeric $\mathrm{Zr}$ species could readily switch between 6 - and 7-coordination through water exchange with the bulk solvent. Judging from the $\Delta \mathrm{p} K_{\mathrm{a}}$ values, water exchange has a minor effect on the $\mathrm{Zr}-\mathrm{OH}_{2}$ acidity as well. According to the calculations the $\mathrm{Zr}-\mathrm{OH}_{2} \mathrm{pK}_{\mathrm{a}}$ values increase in the order $\mathrm{H}_{2} \mathrm{O}<$ $\mathrm{BNPP}<\mathrm{NPP}$, that is with an increase of the negative charge of the ligands, 0, 1-, 2-. As can be seen from Figure 11, the $\Delta \mathrm{p} K_{\mathrm{a}}$ values are spread over a broad range between 0 and 14. Hence, one may expect that the $\mathrm{Zr}-\mathrm{OH}_{2}$ of $\mathrm{POM}-\mathrm{Zr}\left(\mathrm{H}_{2} \mathrm{O}\right)_{n}(n=2,3)$ should be strongly acidic, while the acidity of the water ligands in 
the POM- $\mathrm{Zr}(\mathrm{NPP}$-monodentate $)\left(\mathrm{H}_{2} \mathrm{O}\right)_{\mathrm{n}}(\mathrm{n}=1,2)$ complexes should be comparable with the acidity of solvent water. Thus, it could be expected that at $\mathrm{pD} 6.4$ the monomeric ZrK 1:1 species will most probably contain a $\mathrm{OH}$ nucleophile whereas in the $\mathrm{ZrK}$ 1:1 complexes of NPP (both mono- and bidentate) the $\mathrm{OH}$ ligand will be protonated, with a stabilizing effect that is more pronounced for monodentate than for bidentate NPP. The $\mathrm{Zr}$ $\mathrm{OH}_{2}$ in BNPP complexes is less acidic than in the reference compound, $\mathrm{POM}-\mathrm{Zr}\left(\mathrm{H}_{2} \mathrm{O}\right)_{2}$, with a positive shift of about $5 \mathrm{pK}$ values. Thus, in the case of BNPP it is hard to judge whether the intramolecular $\mathrm{OH}$ nucleophile will be protonated or not at the reaction $\mathrm{pD}$ (6.4). Taking into account that the $\mathrm{p} K_{\mathrm{a}}$ of a $\mathrm{Zr}$ bound water molecule is $0.6^{[22]}$ and assuming that the $p K_{a}$ of the reference $\mathrm{POM}-\mathrm{Zr}\left(\mathrm{H}_{2} \mathrm{O}\right)_{2}$ is close to this value, it seems more realistic to assume predominance of the $-\mathrm{OH}$ than the $-\mathrm{OH}_{2}$ form of the BNPP complex in neutral solution.

By combining the experimental findings with the calculated data the most likely compositions of the intermediate compounds involved in the hydrolysis reaction are proposed (Figure12), and a detailed reaction scheme is provided (Figure 13).

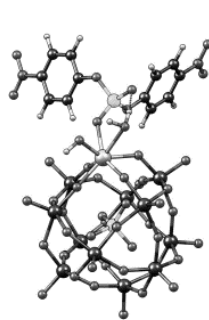

11

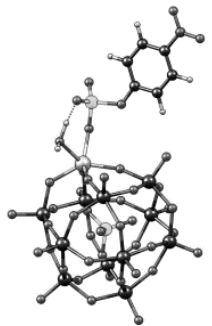

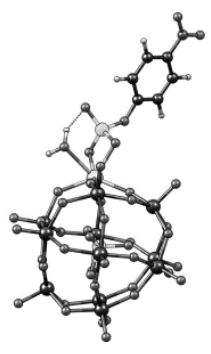

$12 \mathrm{~b}$

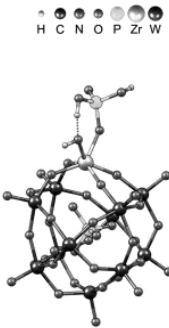

13
Figure 12. DFT optimized structures of the proposed intermediate complexes involved in the $\mathrm{Zr}^{\mathrm{IV}}$-substituted Keggin POM promoted hydrolysis of BNPP.

As shown above, reaction of BNPP both with ZrK 2:2 and ZrK $1: 1$ is endergonic. This may explain the absence of NMR signals that could be attributed to a complex of BNPP with $\mathrm{Zr}^{\mathrm{IV}}$ substituted Keggin POM (I1). However, in the complex POM$\mathrm{Zr}(\mathrm{BNPP})(\mathrm{OH})\left(\mathrm{H}_{2} \mathrm{O}\right)$, presumably formed when BNPP coordinates to ZrK1:1, an intramolecular $\mathrm{OH}$ nucleophile is created (which would in the ZrK 2:2 complex be involved in a $\mu$ $\mathrm{OH}$ bridge), which is a good premise for hydrolytic power. Also, the phosphorus atom of BNPP becomes more positively charged upon coordination to ZrK 1:1 ( $q=0.235$ as compared to 0.173 in free BNPP), indicating an enhanced susceptibility towards nucleophilic attack. Therefore, we believe that the POM$\mathrm{Zr}(\mathrm{BNPP})(\mathrm{OH})\left(\mathrm{H}_{2} \mathrm{O}\right)$ species should be considered as the major player in promoting hydrolytic cleavage of BNPP to NPP (first reaction step, Figure 13) by a mechanism involving intramolecular $\mathrm{OH}$ attack on the substrate phosphorus atom with release of 4-nitrophenol (NP). As evidenced by experiment the resultant NPP ions also interact with the POM, giving rise to an equilibrated mixture of intermediates $12 \mathrm{a}$ and $\mathrm{I} 2 \mathrm{~b}$ and free NPP. DFT calculations revealed that thermodynamically stable complexes of NPP are formed with ZrK 1:1 rather than with ZrK $2: 2$, and that monodentate NPP binding to ZrK $1: 1$ is preferred over bidentate binding. Therefore, we believe that the more intense ${ }^{1} \mathrm{H}$ NMR signals of $12 \mathrm{a}$ most likely correspond to POM$\mathrm{Zr}$ (NPP-monodentate) $\left(\mathrm{H}_{2} \mathrm{O}\right)$ complex, while the less intense NMR signals of $12 \mathrm{~b}$ could be assigned to the less stable complex, POM-Zr(NPP-bidentate) $\left(\mathrm{H}_{2} \mathrm{O}\right)$. Both complexes contain coordinated $\mathrm{H}_{2} \mathrm{O}$ rather than $\mathrm{OH}$. Thus, the mechanism of NPP hydrolysis most likely involves nucleophilic attack by a solvent water molecule on the P-atom of NPP leading to the final products, NP and phosphate ion (second reaction step, Figure 13). The calculations done so far do not provide information about the reaction kinetics and therefore it is hard to judge which of the two intermediates, $12 \mathrm{a}$ or $12 \mathrm{~b}$, is more hydrolytically active. They showed, however, that monodentate NPP binding is more stable and results in a slightly more positive charge on the target P-atom $(q=0.131)$ in $12 \mathrm{a}$ as compared to $12 \mathrm{~b}(q=0.116)$, thus suggesting higher hydrolytic potency of the 12a species.

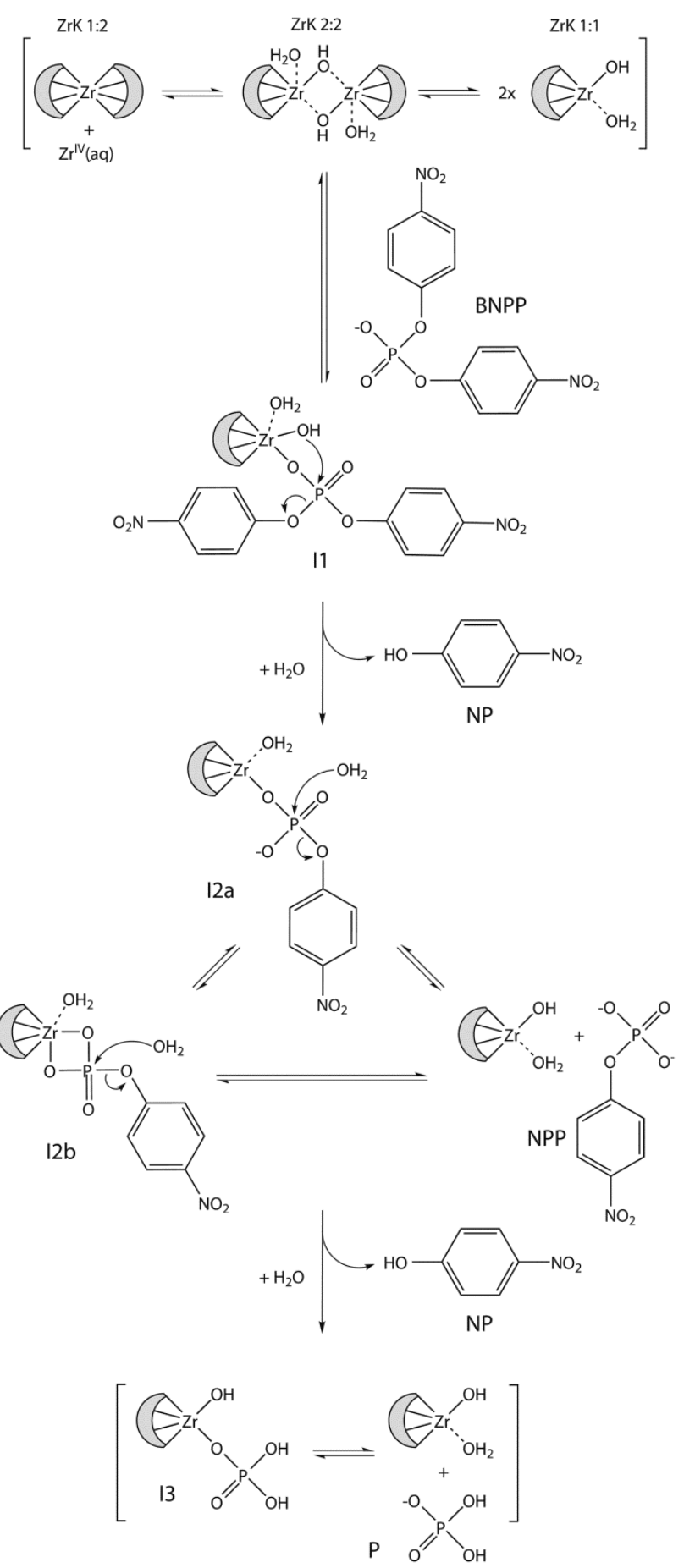

Figure 13. Proposed reaction mechanism of BNPP hydrolysis catalyzed by $\mathrm{Zr}^{\mathrm{IV}}$-substituted Keggin POM. 
As indicated by experiment interaction between the POM and the end product phosphate ions also takes place in the course of the reaction. To elucidate the molecular nature of this species the most plausible complexes of both ZrK 2:2 and ZrK 1:1 with $\mathrm{H}_{2} \mathrm{PO}_{4}{ }_{4}$, the major form at pD 6.4, were modeled. For ZrK 2:2 only bidentate bridging coordination was examined whereas in the case of ZrK 1:1 both mono- and bidentate binding modes were considered. The energy of the bridging complex of ZrK 2:2 was found to be higher than the reactant state by $3.6 \mathrm{kcal} \mathrm{mol}^{-1}$. In contrast, bi- and monodentate coordination of $\mathrm{P}$ to the monomeric POM is preferred by 1.1 and $8.0 \mathrm{kcal} \mathrm{mol}^{-1}$ over the initial state ( $\mathrm{ZrK} \mathrm{2:2}+2 \mathrm{H}_{2} \mathrm{PO}_{4}{ }^{-}$) respectively. Given the above, the NMR signals of 13 could be attributed to a monodentate complex of $\mathrm{P}$ and ZrK 1:1, as illustrated in Figure 12.

\section{Conclusion}

A detailed reaction mechanism for the hydrolysis of the phosphoester bonds in the DNA model substrate bis-4nitrophenyl phosphate (BNPP) catalyzed by the $\mathrm{Zr}^{\mathrm{IV}}$-substituted Keggin type polyoxometalate $\left(\mathrm{Et}_{2} \mathrm{NH}_{2}\right)_{8}\left[\left\{\alpha-\mathrm{PW}_{11} \mathrm{O}_{39} \mathrm{Zr}(\mu\right.\right.$ $\left.\left.\mathrm{OH})\left(\mathrm{H}_{2} \mathrm{O}\right)\right\}\right] \cdot 7 \mathrm{H}_{2} \mathrm{O}$ (ZrK 2:2) was proposed, based on a combination of ${ }^{1} \mathrm{H} /{ }^{31} \mathrm{P}$ NMR spectroscopy and theoretical calculations. ${ }^{31} \mathrm{P}$ DOSY and DFT calculations demonstrate for the first time the presence of the 1:1 Zrv $\mathrm{Zr}^{\mathrm{IV}}$-substituted Keggin type species in aqueous solution. Moreover, this species was identified as the active species responsible for phosphoester bond hydrolysis in BNPP. This is an important finding in the emerging field of metal-substituted polyoxometalate catalysis since aqueous solution speciation studies rarely provide an unambiguous answer to this question. The results also demonstrate the applicability and unraveling power of the still underexplored combination between DOSY NMR and computational methods in POM chemistry. Therefore, this study may allow for a more rational design of metal-substituted POMs, thereby further optimizing their hydrolytic properties and resulting in their broader catalytic applications.

\section{Experimental Section}

Materials: The $\mathrm{Zr}^{\mathrm{IV}}$-substituted Keggin POM, $\left(\mathrm{Et}_{2} \mathrm{NH}_{2}\right)_{8}[\{\alpha-$ $\left.\left.\mathrm{PW}_{11} \mathrm{O}_{39} \mathrm{Zr}(\mu-\mathrm{OH})\left(\mathrm{H}_{2} \mathrm{O}\right)\right\}_{2}\right] \cdot 7 \mathrm{H}_{2} \mathrm{O}$ (ZrK $\left.2: 2\right)^{[15 \mathrm{~b}]}$ and $\left(\mathrm{Et}_{2} \mathrm{NH}_{2}\right)_{10}\left[\mathrm{Zr}\left(\mathrm{PW}_{11} \mathrm{O}_{39}\right)_{2}\right] \cdot 7 \mathrm{H}_{2} \mathrm{O}(\mathrm{ZrK} \mathrm{1:2})^{[15 a]}$ were synthesized as described in literature.Disodium 4-nitrophenyl phosphate (NPP, $\mathrm{C}_{6} \mathrm{H}_{4} \mathrm{NO}_{6} \mathrm{PNa}_{2} \cdot 6 \mathrm{H}_{2} \mathrm{O}$ ), sodium bis-4-nitrophenyl phosphate (BNPP, $\mathrm{C}_{12} \mathrm{H}_{8} \mathrm{~N}_{2} \mathrm{NaO}_{8} \mathrm{P}$ ), $\mathrm{DCl}$, and $\mathrm{NaOD}$ were purchased from Acros.

Sample Preparation: Solutions containing $3.0-6.0 \mathrm{mM}$ of BNPP and $3.0-6.0 \mathrm{mM}$ of $\mathrm{ZrK} \mathrm{2:2}$ were prepared in $\mathrm{D}_{2} \mathrm{O}$. The final $\mathrm{pD}$ of solution was adjusted with minor amounts of concentrated $\mathrm{DCl}(10 \%)$ and $\mathrm{NaOD}(15 \%)$. The $\mathrm{pH}$-meter value was corrected by using the equation: $\mathrm{pD}=\mathrm{pH}$ meter reading + $0.41 .^{[23]}$

NMR Measurements: The NMR spectra were recorded on a Bruker Avance II+ 600 NMR spectrometer using $5 \mathrm{~mm}$ direct detection dual broadband probe, with a gradient coil delivering maximum gradient strength of $53 \mathrm{G} / \mathrm{cm}$. The ${ }^{1} \mathrm{H}$ spectra were referenced to $0.5 \mathrm{mM}$ of 3-(trimethylsilyl)propionic-2,2,3,3-d4 acid added tothe reaction solution. $25 \%$ phosphoric acid was used as ${ }^{31} \mathrm{P}$ external reference. All experiments were performed at a temperature of $298 \mathrm{~K}$, except ${ }^{31} \mathrm{P}$ DOSY spectra measured at $283 \mathrm{~K}$. The ${ }^{1} \mathrm{H}$ DOSY spectra were measured using stimulated echo based pulse sequence, with bipolar sine shaped gradient pulses and integrated water suppression scheme with 3-9-19 binomial pulse train. All spectra were recorded with $32 \mathrm{~K}$ time domain data points in $\mathrm{t} 2$ dimension, 32 gradient strength increments, diffusion delay $(\Delta)$ of $100 \mathrm{~ms}$, gradient pulse length ( $\delta$ ) of $4 \mathrm{~ms}$, relaxation delay of 3s and 64 transients for each gradient step. The gradient strength was varied from 2 to $70 \%$ of the maximum gradient output of the gradient unit (from 0.68 to $23.84 \mathrm{G} / \mathrm{cm}$ ) to ensure complete signal attenuation. The spectra were processed with an exponential window function (line broadening factor 0.5 ), 32K data points in F2 dimension and 512 data points in the diffusion dimension, using the fitting routine integrated in Topspin3.2 package. The 2D EXSY spectra were recorded with the Bruker program noesygpphw5 with water suppression using watergate W5 pulse scheme. The spectra were recorded with a spectral width of $8000 \mathrm{~Hz}, 2 \mathrm{~K}$ data points in $t 2$ time domain and $256 t 1$ increments with 64 transients each, and a relaxation delay of $3 \mathrm{~s}$. The spectra were recorded for each sample with three different mixing times of 100, 200 and $300 \mathrm{~ms}$. A sine window function ( $\mathrm{ssb}=2$ ) and zero-filling were applied in both dimensions prior to Fourier transformation, to give $4 \mathrm{~K} \times 4 \mathrm{~K}$ data matrix in the frequency domain. The ${ }^{31} \mathrm{P}$ DOSY spectra were measured at a temperature of $283 \mathrm{~K}$ using a stimulated echo based pulse sequence, with bipolar sine shaped gradient pulses. The spectra were acquired with $64 \mathrm{~K}$ time domain data points in $\mathrm{t} 2$ dimension, 32 gradient strength increments, diffusion delay of $200 \mathrm{~ms}$, gradient pulse length of 9 ms, 128 transients for each gradient step and a relaxation delay of $6 \mathrm{~ms}$. The gradient strength was incremented from 2 to $80 \%$ of the maximum gradient output (from 0.68 to $27.25 \mathrm{G} / \mathrm{cm}$ ). The spectra were processed with exponential window function (line broadening factor 5), $64 \mathrm{~K}$ data points in $\mathrm{F} 2$ and 258 data points in the diffusion dimension. The evaluation of the diffusion coefficients was performed by fitting the diffusion profile (the normalized signal intensity as a function of the gradient strength $\mathrm{G})$ at the chemical shift of each signal in the DOSY spectrum with an exponential function using the variant of Stejskal-Tanner equation adapted to the particular pulse sequence used.

Computational Procedure: All calculations were performed with the ORCA program system, ${ }^{[24]}$ version 3.0. Geometry optimizations were carried out using DFT with the BP86 ${ }^{[25]}$ functional in combination with the resolution of the identity (RI) technique. ${ }^{[26]}$ The def2-SVP basis sets ${ }^{[27]}$ with the auxiliary def2SVP/J Coulomb fitting basis sets ${ }^{[28]}$ were used for all atoms. The $\mathrm{Zr}$ and $\mathrm{W}$ core electrons were described with the MWB28 and MWB60 Stuttgart-Dresden effective core potentials (ECPS) respectively ${ }^{[29]}$. Increased integration grids (Grid4 in ORCA convention) and tight SCF convergence criteria were applied. All geometry optimizations were performed in solvent environment by means of the conductor-like screening model (COSMO), ${ }^{[30]}$ using the default parameters of water. To ensure that the optimized structures are minima on the potential energy surface and to obtain the thermochemical data vibrational frequencies were computed (by numerical calculation of the Hessian matrix) using the standard rigid rotor-harmonic oscillator approximation. Furthermore, single-point (SP) energy calculations were 
performed by means of the hybrid density functional B3LYP ${ }^{[31]}$ with more extended basis sets, i.e. def2-TZVP ${ }^{[27]}$ (retaining the ECPs for $\mathrm{Zr}$ and $\mathrm{W}$ atoms), conjugated with the COSMO solvation model. The RI approximation with the auxiliary def2TZVP/J Coulomb fitting basis sets ${ }^{[28]}$ as well as the chain-ofspheres approximation to the exact exchange (RIJCOSX) ${ }^{[32]}$ were utilized with refined integration grids (Grid5 and GridX5 in ORCA convention) and tight SCF convergence criteria. To account for dispersion interactions (van der Waals effects) Grimme's atom-pairwise dispersion correction with BeckeJohnson damping (D3BJ) ${ }^{[33]}$ was applied. Atomic charges were calculated by means of Löwdin population analysis. ${ }^{[34]}$

The aqueous phase free energy of the species were estimated as

$$
G_{a q}^{*}=E_{e l}^{\mathrm{B} 3 \mathrm{LYP}}+E_{d i s p}^{\mathrm{D} 3 \mathrm{BJ}}+\left(G^{0}-E_{e l}\right)^{\mathrm{BP} 86}+\Delta G_{h y d r}^{*}+\Delta G^{0 \rightarrow *}(1)
$$

where $E_{e l}^{\mathrm{B} 3 \mathrm{LYP}}$ is the SP B3LYP/def2-TZVP electronic energy, $E_{\text {disp }}^{\mathrm{D} 3 \mathrm{BJ}}$ is the $\mathrm{D} 3 \mathrm{BJ}$ dispersion correction and $\Delta G_{h y d r}^{*}$ is the free energy change due to the hydration, as derived from COSMO model, after correction for the solute charge density lying outside the cavity. The $\left(G^{0}-E_{e l}\right)^{\mathrm{BP} 86}$ term denotes the thermochemical corrections ( $1 \mathrm{~atm}, 298.15 \mathrm{~K}$ ) derived from the BP86 frequency calculations. The $\Delta G^{0 \rightarrow *}$ term in Eq. 1 is the standard state correction accounting for the free energy change of 1 mole of

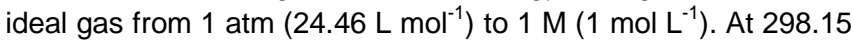
$\mathrm{K}, \Delta G^{0 \rightarrow *}$ is $1.89 \mathrm{kcal} \mathrm{mol}^{-1}$. For $\mathrm{H}_{2} \mathrm{O}$ solvated in liquid water, which has a standard state concentration of $55.34 \mathrm{M}$, a concentration correction term $R T \ln \left(\left[\mathrm{H}_{2} \mathrm{O}\right]\right)$, accounting for the free energy change of 1 mole of $\mathrm{H}_{2} \mathrm{O}$ gas from $1 \mathrm{M}$ to $55.34 \mathrm{M}$ liquid state, should also be included. ${ }^{[35]}$ At $298.15 \mathrm{~K}, R T \ln (55.34)$ $2.38 \mathrm{kcal} \mathrm{mol}^{-1}$.

\section{Acknowledgements}

T.N.P-V. and P.S. thank FWO Flanders and KU Leuven for financial support. T.K.N.L. thanks the Vietnamese Government and KU Leuven for a doctoral fellowship. G.A. thanks FWO Flanders for a post-doctoral fellowship. K.P., T.N.P-V. and T.T.M. thank FWO Flanders for financial support under project G.0260.12. The authors acknowledge the CMST COST Action (CM1203, Polyoxometalate Chemistry for Molecular Nanoscience) for financial support in terms of STSM applications. The computational resources and services used in this work were provided by the VSC (Flemish Supercomputer Center), funded by the Hercules Foundation and the Flemish Government - department EWI. The calculations were performed on the HPC cluster Tier-2 of KU Leuven.

Keywords: • Hydrolysis • Zirconium - NMR spectroscopy - Polyoxometalates • DFT modeling

a)F. H. Westheimer, Science 1987, 235, 1173-1178; b)N. H Williams, J. Chin, Chemical Communications 1996, 131-132; c)J. Chin, M. Banaszczyk, V. Jubian, X. Zou, Journal of the American Chemical Society 1989, 111, 186-190.

[2] J. A. Cowan, Chemical Reviews 1998, 98, 1067-1087.

[3] J. Chin, Current Opinion in Chemical Biology 1997, 1, 514-521.

[4] E. L. Hegg, J. N. Burstyn, Coordination Chemistry Reviews 1998 , $173,133-165$.
[5]

a)S. J. Franklin, Current Opinion in Chemical Biology 2001, 5, 201208; b)A. Sreedhara, J. A. Cowan, Journal of Biological Inorganic Chemistry 2001, 6, 337-347; c)J. A. Cowan, Current Opinion in Chemical Biology 2001, 5, 634-642; d)R. Kramer, Coordination Chemistry Reviews 1999, 182, 243-261.

[6] a)A. Proust, R. Thouvenot, P. Gouzerh, Chemical Communications 2008, 1837-1852; b)D. L. Long, R. Tsunashima, L. Cronin, Angewandte Chemie-International Edition 2010, 49, 1736-1758.

[7] a)M. Carraro, S. Gross, Materials 2014, 7, 3956-3989; b)A. Proust, B. Matt, R. Villanneau, G. Guillemot, P. Gouzerh, G. Izzet, Chemical Society Reviews 2012, 41, 7605-7622.

[8] H. Stephan, M. Kubeil, F. Emmerling, C. E. Müller, European Journal of Inorganic Chemistry 2013, 2013, 1585-1594.

[9] a)N. V. Izarova, M. T. Pope, U. Kortz, Angewandte Chemie International Edition 2012, 51, 9492-9510; b)A. Sartorel, M. Bonchio, S. Campagna, F. Scandola, Chemical Society Reviews 2013, 42, 2262-2280.

a)C. Boglio, G. Lemiere, B. Hasenknopf, S. Thorimbert, E. Lacote, M. Malacria, Angewandte Chemie-International Edition 2006, 45, 3324-3327; b)C. Boglio, K. Micoine, P. Remy, B. Hasenknopf, S Thorimbert, E. Lacote, M. Malacria, C. Afonso, J.-C. Tabet, Chemistry-a European Journal 2007, 13, 5426-5432.

[11] a)H. G. T. Ly, G. Absillis, T. N. Parac-Vogt, Dalton Transactions 2013, 42, 10929-10938; b)H. G. T. Ly, G. Absillis, S. R. Bajpe, J. A. Martens, T. N. Parac-Vogt, European Journal of Inorganic Chemistry 2013, 2013, 4601-4611; c)K. Stroobants, G. Absillis, E. Moelants, P. Proost, T. N. Parac-Vogt, Chemistry - A European Journal 2014, 20, 3894-3897; d)K. Stroobants, E. Moelants, H. G. T. Ly, P. Proost, K. Bartik, T. N. Parac-Vogt, Chemistry - A European Journal 2013, 19, 2848-2858; e)K. Stroobants, V. Goovaerts, G. Absillis, G. Bruylants, E. Moelants, P. Proost, T. N. Parac-Vogt, Chemistry - A European Journal 2014, 20, 95679577; f)S. Vanhaecht, G. Absillis, T. N. Parac-Vogt, Dalton Transactions 2013, 42, 15437-15446; g)G. Absillis, T. N. ParacVogt, Inorganic Chemistry 2012, 51, 9902-9910; h)A. Sap, G. Absillis, T. N. Parac-Vogt, Dalton Transactions 2014. DOI: 10.1039/C4DT01477D.

[12] a)S. Vanhaecht, G. Absillis, T. N. Parac-Vogt, Dalton Transactions 2012, 41, 10028-10034; b)G. Absillis, E. Cartuyvels, R. Van Deun T. N. Parac-Vogt, Journal of the American Chemical Society 2008, 130, 17400-17408.

[13] T. K. N. Luong, G. Absillis, P. Shestakova, T. N. Parac-Vogt, European Journal of Inorganic Chemistry 2014 DOI:10.1002/ejic.201402735.

[14] a)M. N. Sokolov, N. V. Izarova, E. V. Peresypkina, D. A Mainichev, V. P. Fedin, Inorganica Chimica Acta 2009, 362, 3756 3762; b)G. Absillis, T. N. Parac-Vogt, Inorganic Chemistry 2012 51, 9902-9910; c)N. Dupre, P. Remy, K. Micoine, C. Boglio, S. Thorimbert, E. Lacote, B. Hasenknopf, M. Malacria, Chemistry-a European Journal 2010, 16, 7256-7264; d)K. Nomiya, Y. Sakai, S. Matsunaga, European Journal of Inorganic Chemistry 2011, 2011, 179-196

[15] a)C. N. Kato, A. Shinohara, K. Hayashi, K. Nomiya, Inorganic Chemistry 2006, 45, 8108-8119; b)K. Nomiya, Y. Saku, S. Yamada, W. Takahashi, H. Sekiya, A. Shinohara, M. Ishimaru, Y. Sakai, Dalton Transactions 2009, 5504-5511.

a)K. Ulrich, M. Sanders, F. Grinberg, P. Galvosas, S. Vasenkov Langmuir 2008, 24, 7365-7370; b)M. Valentini, A. Vaccaro, A. Rehor, A. Napoli, J. A. Hubbell, N. Tirelli, Journal of the American Chemical Society 2004, 126, 2142-2147; c)T. J. Zhao, H. W. Beckham, Macromolecules 2003, 36, 9859-9865; d)P. S. Denkova L. Van Lokeren, R. Willem, Journal of Physical Chemistry B 2009, 113, 6703-6709; e)P. Denkova, D. Momekova, S. Rangelov, N. Lambov, R. Willem, Journal of Controlled Release 2010, 148, E47E48; f)A. Kowalczuk, E. Stoyanova, V. Mitova, P. Shestakova, G. Momekov, D. Momekova, N. Koseva, International Journal of Pharmaceutics 2011, 404, 220-230.

[17] a)Y. Cohen, L. Avram, L. Frish, Angewandte Chemie-International Edition 2005, 44, 520-554; b)A. Pastor, E. Martinez-Viviente, Coordination Chemistry Reviews 2008, 252, 2314-2345; c)S. Han, 
Z. Ma, R. Hopson, Y. Wei, D. Budil, S. Gulla, B. Moulton, Inorganic Chemistry Communications 2012, 15, 78-83. a)I. Fernandez, E. Martinez-Viviente, F. Breher, P. S. Pregosin, Chemistry-a European Journal 2005, 11, 1495-1506; b)E. Martinez-Viviente, H. Ruegger, P. S. Pregosin, J. Lopez-Serrano, Organometallics 2002, 21, 5841-5846; c)D. Nama, P. G. A. Kumar P. S. Pregosin, Magnetic Resonance in Chemistry 2005, 43, 246250.

a)J.-F. Lemonnier, S. Floquet, A. Kachmar, M.-M. Rohmer, M. Benard, J. Marrot, E. Terazzi, C. Piguet, E. Cadot, Dalton Transactions 2007, 3043-3054; b)S. Floquet, S. Brun, J.-F. Lemonnier, M. Henry, M.-A. Delsuc, Y. Prigent, E. Cadot, F. Taulelle, Journal of the American Chemical Society 2009, 131 17254-17259; c)J.-F. Lemonnier, S. Floquet, J. Marrot, E. Terazzi C. Piguet, P. Lesot, A. Pinto, E. Cadot, Chemistry-a European Journal 2007, 13, 3548-3557; d)M. V. Vasylyev, S. Gatard, I. BarNahum, L. Konstantinovski, E. J. Wachtel, R. Neumann, Journal of Cluster Science 2006, 17, 235-243; e)L. Van Lokeren, E. Cartuyvels, G. Absillis, R. Willem, T. N. Parac-Vogt, Chemical Communications 2008, 2774-2776; f)M.-P. Santoni, A. K. Pal, G. S. Hanan, M.-C. Tang, K. Venne, A. Furtos, P. Menard-Tremblay, C. Malveau, B. Hasenknopf, Chemical Communications 2012, 48 200-202; g)P. Yin, C. P. Pradeep, B. Zhang, F.-Y. Li, C. Lydon, M. H. Rosnes, D. Li, E. Bitterlich, L. Xu, L. Cronin, T. Liu, Chemistry-a European Journal 2012, 18, 8157-8162; h)M. F. Misdrahi, M. Wang, C. P. Pradeep, F.-Y. Li, C. Lydon, L. Xu, L. Cronin, T. Liu, Langmuir 2011, 27, 9193-9202; i)P. Shestakova, G. Absillis, F. J. Martin-Martinez, F. De Proft, R. Willem, T. N. Parac-Vogt, Chemistry-a European Journal 2014, 20, 5258-5270; j)K Stroobants, G. Absillis, P. Shestakova, R. Willem, T. Parac-Vogt, Journal of Cluster Science 2014, 25, 855-866.

. Kholdeeva G. M. Maksimov, R. I. Maksimovskaya, M. P. Vanina, T. A. Trubitsina, D. Y. Naumov, B. A. Kolesov, N. S Antonova, J. J. Carbo, J. M. Poblet, Inorganic Chemistry 2006, 45 7224-7234.

[21] P. Jiménez-Lozano, J. J. Carbó, A. Chaumont, J. M. Poblet, A. Rodríguez-Fortea, G. Wipff, Inorganic Chemistry 2014, 53, 778786.
[22] J. Burgess, Halsted Press (Wiley), New York, 1978

[23] P. K. Glasoe, F. A. Long, Journal of Physical Chemistry 1960, 64, 188.

[24] F. Neese, Wiley Interdisciplinary Reviews: Computational Molecular Science 2012, 2, 73-78.

[25] a)A. D. Becke, Physical Review A 1988, 38, 3098-3100; b)J. P. Perdew, Physical Review B 1986, 33, 8822-8824.

[26] a)K. Eichkorn, O. Treutler, H. Öhm, M. Häser, R. Ahlrichs, Chemical Physics Letters 1995, 242, 652-660; b)K. Eichkorn, F. Weigend, O. Treutler, R. Ahlrichs, Theoretical Chemistry Accounts 1997, 97, 119-124; c)F. Neese, Journal of Computational Chemistry 2003, 24, 1740-1747.

[27] F. Weigend, R. Ahlrichs, Physical Chemistry Chemical Physics 2005, 7, 3297-3305

[28] F. Weigend, Physical Chemistry Chemical Physics 2006, 8, 10571065.

[29] D. Andrae, U. Häußermann, M. Dolg, H. Stoll, H. Preuß, Theoretica chimica acta 1990, 77, 123-141.

[30] A. Klamt, G. Schuurmann, Journal of the Chemical Society, Perkin Transactions 2 1993, 799-805.

[31] a)A. D. Becke, The Journal of Chemical Physics 1993, 98, 56485652; b)C. Lee, W. Yang, R. G. Parr, Physical Review B 1988, 37 , 785-789; c)P. J. Stephens, F. J. Devlin, C. F. Chabalowski, M. J. Frisch, The Journal of Physical Chemistry 1994, 98, 11623-11627.

[32] F. Neese, F. Wennmohs, A. Hansen, U. Becker, Chemical Physics 2009, 356, 98-109.

[33] a)S. Grimme, J. Antony, S. Ehrlich, H. Krieg, The Journal of Chemical Physics 2010, 132, -; b)S. Grimme, S. Ehrlich, L. Goerigk, Journal of Computational Chemistry 2011, 32, 14561465.

[34] P. O. Löwdin, The Journal of Chemical Physics 1950, 18, 365-375. [35] a)J. R. Pliego, J. M. Riveros, The Journal of Physical Chemistry A 2001, 105, 7241-7247; b)V. S. Bryantsev, M. S. Diallo, W. A. Goddard lii, The Journal of Physical Chemistry B 2008, 112, 97099719. 


\section{Entry for the Table of Contents (Please choose one layout)}

Layout 1:

\section{FULL PAPER}

\section{Text for Table of Contents}

A detailed reaction mechanism for bis-4nitrophenyl phosphate (BNPP) hydrolysis in the presence of the $\mathrm{Zr}^{\mathrm{IV}}$ substituted Keggin type polyoxometalate $\left(\mathrm{Et}_{2} \mathrm{NH}_{2}\right)_{8}\left[\left\{\alpha-\mathrm{PW}_{11} \mathrm{O}_{39} \mathrm{Zr}(\mu-\right.\right.$ $\left.\left.\mathrm{OH})\left(\mathrm{H}_{2} \mathrm{O}\right)\right\}_{2}\right] \cdot 7 \mathrm{H}_{2} \mathrm{O} \quad(\mathrm{ZrK} \quad 2: 2) \quad$ was proposed based on ${ }^{1} \mathrm{H},{ }^{31} \mathrm{P}$, EXSY and DOSY NMR studies, and supported by DFT calculations.

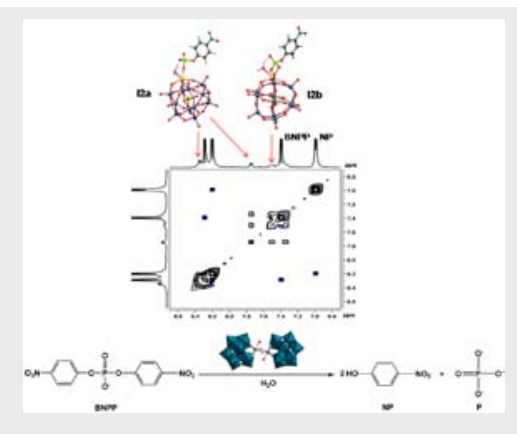

Author(s), Corresponding Author(s)* Thi Kim Nga Luong, ${ }^{[\mathrm{a}]}$ Pavletta

Shestakova, ${ }^{[\mathrm{a}],[\mathrm{b}]}$ Tzvetan T. Mihaylov, ${ }^{[\mathrm{c}]}$ Gregory Absillis, ${ }^{[\mathrm{a}]}$ Kristine Pierloot, ${ }^{[\mathrm{c}]}$ and Tatjana N. Parac-Vogt ${ }^{\star[a]}$ Page No. - Page No.

Title

Multinuclear diffusion NMR Spectroscopy and DFT modeling: a powerful combination for unraveling the mechanism of phosphoester bond hydrolysis catalyzed by metalsubstituted polyoxometalates

\section{Layout 2:}

\section{FULL PAPER}

Author(s), Corresponding Author(s)*

Page No. - Page No.

Title

Text for Table of Contents 